\title{
Polymer and ceramic nanocomposites for aerospace applications
}

\author{
Vivek T. Rathod ${ }^{1} \cdot$ Jayanth S. Kumar $^{1} \cdot$ Anjana Jain $^{1}$
}

Received: 29 June 2017/ Accepted: 29 August 2017/Published online: 9 September 2017

(c) The Author(s) 2017. This article is an open access publication

\begin{abstract}
This paper reviews the potential of polymer and ceramic matrix composites for aerospace/space vehicle applications. Special, unique and multifunctional properties arising due to the dispersion of nanoparticles in ceramic and metal matrix are briefly discussed followed by a classification of resulting aerospace applications. The paper presents polymer matrix composites comprising majority of aerospace applications in structures, coating, tribology, structural health monitoring, electromagnetic shielding and shape memory applications. The capabilities of the ceramic matrix nanocomposites to providing the electromagnetic shielding for aircrafts and better tribological properties to suit space environments are discussed. Structural health monitoring capability of ceramic matrix nanocomposite is also discussed. The properties of resulting nanocomposite material with its disadvantages like cost and processing difficulties are discussed. The paper concludes after the discussion of the possible future perspectives and challenges in implementation and further development of polymer and ceramic nanocomposite materials.
\end{abstract}

Keywords Nanocomposite - Aerospace - Tribology · Structural health monitoring $\cdot$ Polymer matrix $\cdot$ Ceramic matrix

Anjana Jain

janjana@nal.res.in

1 Materials Science Division, National Aerospace Laboratories, Bengaluru 560017, India

\section{Introduction}

Nanocomposites are the materials of twenty-first century having an annual growth rate of $25 \%$ due to their multifunctional capabilities. With unique design possibilities and properties, they attract the attention of researchers worldwide. Due to the possibility of combining desired properties, nanocomposites are expanding their potentials in aerospace applications and in future space missions. Selection of the constituents of nanocomposites (matrix and nanofillers) leads to the improvement of certain desired properties. For aerospace applications, mechanical, thermal, electrical, chemical and biodegradable properties are of interest. Chemical property like resistance or passiveness to corrosion is of prime importance. Apart from low weight requirements, aerospace structures pose requirement of mechanical properties for design like strength, toughness, fatigue life, impact resistance and scratch resistance. Aircrafts flying at high altitudes require properties like low solar absorption, radiation resistance, high thermal emissivity and electrical conductivity. Due to increasing use of nanocomposites, handling their disposal after the service life is of great concern. Thus, biodegradable property is also being preferred apart from their functional properties (Gangopadhyay and De 2000; Ray and Bousmina 2005; Pandey et al. 2005). Being environmentally friendly, few nanocomposites have opened the possibilities of clean technologies (Choa et al. 2003). Proper choice of nanofillers and matrix is a key in achieving the desired multifunctional properties that are required by many aerospace applications.

Nanofillers with low volume of $1-5 \%$ can enhance the properties of composite materials that are comparable to those of conventional microfillers with $15-40 \%$ volume. Nanofillers have exceptional properties since they have 
basic structure at crystal level that is defect free. Nanomaterials can be classified as per the dimensions (Alexandre and Dubois 2000). Iso-dimensional (three-dimensional) nanoparticles have the three dimensions in nanoscale like silica, metal particles and semiconductor particles (Herron and Thorn 1998). Nanotubes or whiskers are second kind of two-dimensional nanoparticles that have two dimensions in nanometer scale $(<100 \mathrm{~nm})$ with the third dimension forming an elongated structure (aspect ratio more than 100) (Favier et al. 1997). Fillers like sheets are one-dimensional with one dimension like the thickness is in nanometer range $(1 \mathrm{~nm})$ and the other two dimensions have an aspect ratio $>25$ (Ray and Okamoto 2003; Alexandre and Dubois 2000). Each type of nanofiller has its own advantages, disadvantages and unique properties.

Varieties of nanocomposites have been evolved depending upon the type of matrix used for which they are widely classified into three categories (as in case of microcomposites) as polymer matrix nanocomposites (PMNCs), ceramic matrix nanocomposites (CMNCs) and metal matrix nanocomposites. PMNC and CMNC have found applications for aircrafts and spacecrafts (see Fig. 1), whereas the use of metal matrix nanocomposite is limited due to the limitations of processing. Due to their ease of production, PMNCs have been widely used (Alexandre and Dubois 2000; Pandey et al. 2005; Thostenson et al. 2005; Choi and Awaji 2005; Ray and Bousmina 2005; Andrews and Weisenberger 2004). Disadvantages such as low modulus and shear strength of polymer matrix have been overcome by adding fibers, whiskers, platelets and carbon nanotubes (CNTs). Several inorganic fillers increase mechanical strength, impact strength, thermal stability and flame retardancy, which are required for aerospace applications (Fischer 2003). Future space missions are being planned which require large lightweight parts maintaining properties for over 30 years in very harsh environments involving exposure to atomic oxygen and solar radiation (Thompson et al. 2003). PMNCs such as polymer/aluminum (polymer/Al) and polymer/alumina (polymer/ $\mathrm{Al}_{2} \mathrm{O}_{3}$ ) have improved ballistic performance (Meda et al. 2005) for which they have been used in preparing rocket propellant. However, challenges arise when these properties of nanofillers have to be realized in nanocomposites. This deficiency is due to poorly dispersed nanoparticles and nanoparticle-matrix interaction (Andrews and Weisenberger 2004; Nalwa 2000; Dresselhaus et al. 2001). Depending upon the type of matrix used, functionalization of nanofillers improves dispersion and interaction within the matrix.

Ceramic matrix nanocomposites combine the properties of ceramics like wear resistance, high thermal stability and chemical stability with the properties of nanofillers (Sternitzke 1997; Choi and Awaji 2005; Peigney et al. 2000). Nanofillers such as whiskers, fibers and platelets increase the fracture toughness of the ceramics, mitigating their brittleness (Becher 1991). In addition, these reinforcements arrest the crack and prevent its propagation. Phase transition and volume expansion in CMNC imparts toughening and

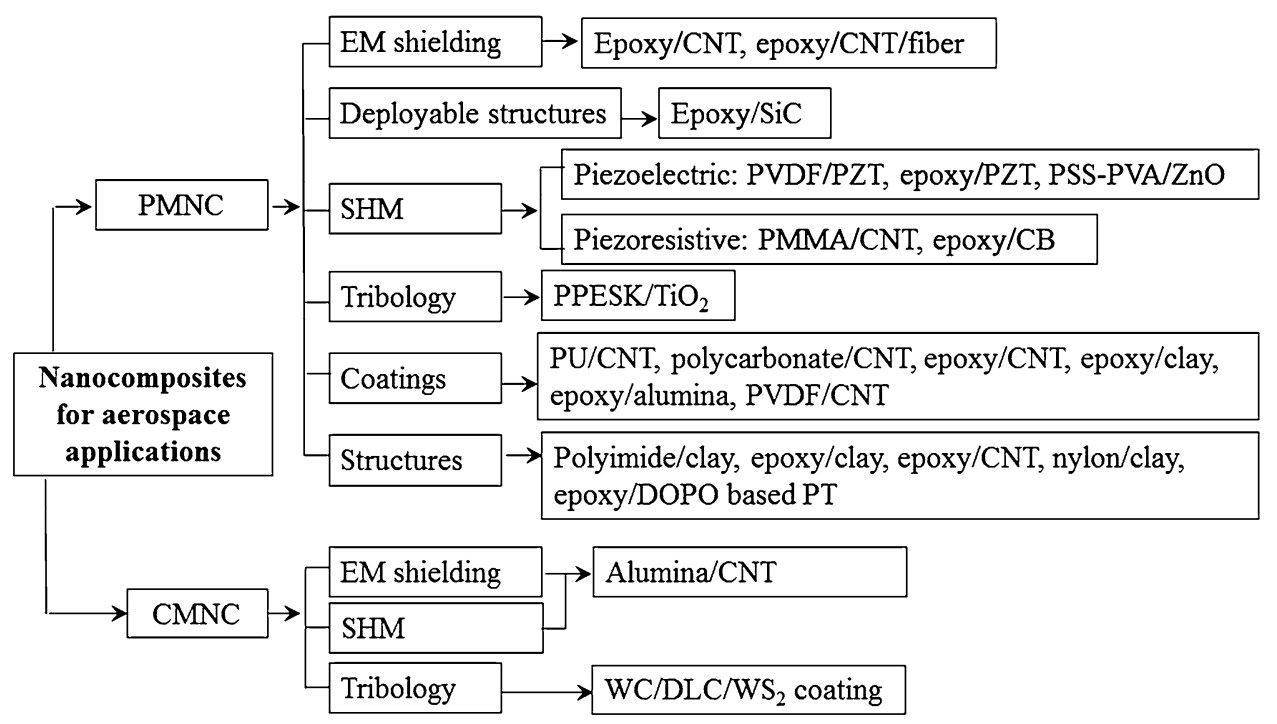

Fig. 1 Nanocomposites for aerospace applications. Abbreviations used in this figure are: $P M N C$ polymer matrix nanocomposite; $C M N C$ ceramic matrix nanocomposite; DOPO 10-dihydro-9-xa-10-phosphaphenanthrene-10-oxide; $P T$ phosphorus tetraglycidyl; $E M$ electro magnetic; SHM structural health monitoring; PVA poly(venyl alcohol); $P U$ polyurethane; $C N T$ carbon nanotube; $P V D F$ Poly(vinilidene fluoride); PPESK poly(phthalazinone ether sulfone ketone); $\mathrm{TiO}_{2}$ titanium dioxide; PMMA polymethyl methacrylate; $P Z T$ lead zirconate titanate; $C B$ carbon black; $W C$ tungsten carbide; $D L C$ diamond-like carbon; $\mathrm{WS}_{2}$ tungsten sulfide; $\mathrm{SiC}$ silicon carbide, $P S S$ poly(sodium 4-styrenesulfonate) 
strengthening (Awaji et al. 2002). Nanocomposites like alumina/silicon carbide $\left(\mathrm{Al}_{2} \mathrm{O}_{3} / \mathrm{SiC}\right)$ show increase in fracture toughness arising from the crack-bridging mechanism of nanosized reinforcements (Ferroni et al. 2001). Incorporation of nanofibers in ceramic matrix results in high toughness with superior failure properties (She et al. 2000). The discovery of CNTs (Iijima 1991) has led to the fabrication of multifunctional ceramic composites possessing improved mechanical, thermal and electrical properties (Biercuk et al. 2002; Ounaies et al. 2003; Weisenberger et al. 2003; Cho et al. 2009). Applications of CNT-woven fibers into textiles have added new scope in the area of nanocomposites (Dalton et al. 2003). CNTs have typically 500 times more surface area based on equivalent volume of a carbon fiber with high aspect ratio (Andrews and Weisenberger 2004). A small number of defects per unit length impart very high tensile strength, electrical conductivity and thermal conductivity in the CMNCs.

Metal matrix nanocomposites consisting of metal matrix with nanoreinforcements combine ductility and toughness with high strength in shear and compression. These properties make them very much suitable for aerospace applications as structural materials (Tjong and Wang 2004). However, metal matrix nanocomposites face several processing challenges for their migration into aerospace applications. A chart in Fig. 1 shows the PMNCs and CMNCs suitable for aerospace applications. Properties of nanocomposites are controlled by adjusting the properties, interaction with matrix, shape, arrangement and volume fraction of nanofillers. Reinforcement size, morphology, inter-reinforcement distance and the reinforcement-matrix interaction control the performance and bulk properties of the nanocomposite. Following the chart in Fig. 1, this paper reviews the properties and potentials of PMNCs and CMNCs in aerospace applications. Aerospace and space industries are more diverse which include freight haulers, military vehicles, satellites, spacecraft, space launch systems, microaerial vehicles, unmanned aerial vehicles, rotorcraft, ground-based systems etc. In the present paper, we focus on the structural applications of nanocomposites suitable for aerospace and space vehicles.

\section{Polymer matrix nanocomposites}

Polymers are macromolecules made up of the repeated units (monomers) connected by covalent bonds. By the dispersion of nanomaterials in polymers, the nanostructure of polymers can be modified. The polymer holds the reinforcement simultaneously retaining the properties of polymer. Polymer nanocomposites are classified into three categories depending upon the reinforcement type. These are discontinuous reinforcement nanocomposites, layered reinforcement nanocomposites and nanofiber or CNT-reinforced nanocomposites. The properties based on nanostructure and morphology of various PMNCs and their corresponding aerospace applications are discussed next.

\section{Structural applications}

In some applications, apart from being lightweight, high performance is of prime importance in aerospace structures e.g., equipment enclosures, aircraft interiors, coatings, cockpit, crew gear, heat shrinkage tubing, space durable mirrors, housings, shrouds, nozzles and solar array substrates. Composite materials offer chemical stability and fire resistance apart from the advantage of low operating cost due to their lightweight. Three major drawbacks limit the applicability of composites in most aerospace structures. Firstly, a higher electrical resistance leads to the limitation for applications like electromagnetic shielding, circuits, antennas and lightning strike protection (Peng 2011). Secondly, lower thermal conductivity of composites increases the load on deicing systems based on electrical heaters. Thirdly, composites are less resistant to impact and suffer from moisture absorption, environmental degradation and aging with time (Mahieux 2006; Martin 2008). Depending upon the matrix and filler used, many solutions have been offered by nanocomposites to overcome these limitations. Some of the nanocomposites and their aircraft applications are discussed next.

\section{Polyimide/clay}

Clay or layered silicates (LS) are the nanofillers that intercalate within the polymer to form layered nanocomposites. These are readily available at low cost and yield predictable stiffening in the nanocomposites. The ability to tune the surface chemistry via ion exchange reactions with organic and inorganic cations yields strong bonding between LS and polymer matrix. Due to the easy availability and well-known intercalation chemistry (Theng 1979), clays are widely used in PMNC (Alexandre and Dubois 2000). Compared to microfiber composites, LSbased nanocomposites show improvements in moduli, strength, heat resistance and biodegradability along with decreased flammability and gas permeability. These improvements make LS-based nanocomposites attractive for aerospace applications (Bharadwaj 2001; Ray et al. 2002; Giannelis 1998). Polyimide/clay nanocomposite is prepared by sol-gel process that involves embedding monomers and organic molecules on sol-gel matrices. Chemical bonds formed by the introduction of organic groups lead to the formation of sol-gel matrix within the polymer, simultaneously forming organic/inorganic networks (Avadhani and Chujo 1997). 
Polyimide/clay nanocomposites show enhanced stress and elongation at failure (Yano et al. 1997). Clay with montmorillonite (MMT) exchanged by hexadecylammonium with loading up to $5 \mathrm{wt} \%$ increases the bulk properties. Above this loading, the properties degrade by increasing brittleness. Increase in storage modulus is seen at any temperature as shown in Fig. 2, for polyimide-based nanocomposite filled with $2 \mathrm{wt} \%$ of organic clay. With such an improvement, glass transition temperature also decreases with increasing clay content. A greater improvement in mica-based nanocomposite is seen due to silicate layers with length of $\sim 218 \mathrm{~nm}$ and thickness of $\sim 1 \mathrm{~nm}$. Mica and MMT clays have exfoliated structures, whereas aponite has a partially exfoliated-intercalated structure and hectorite-based nanocomposite has intercalated morphology. Polymer/LS possess gas barrier properties due to tortuous (maze) path created by LS as shown in Fig. 3 (Ray and Okamoto 2003, Bourbigot et al. 2000, Yano et al. 1997). The tortuosity factor $T_{\mathrm{F}}$ is related to silicate length $l_{\mathrm{S}}$, silicate thickness $W_{\mathrm{F}}$ and volume fraction of the nanocomposites $V_{\mathrm{F}}$ by

$T_{\mathrm{F}}=1+\frac{l_{\mathrm{S}}}{2 W_{\mathrm{F}}} V_{F}$

The relative permeability coefficient $P_{\mathrm{R}}$ is the ratio of permeability coefficient of composite and polymer matrix, respectively. Relative permeability coefficient is found to be inverse of tortuosity factor $P_{\mathrm{R}}=1 / T_{\mathrm{F}}$. Thus, permeability coefficient is smaller if the length of silicate is longer. Tortuosity effects the permeability of nanocomposite $P_{\mathrm{S}}$ by the relation

$P_{\mathrm{S}}=P_{\mathrm{P}}\left(\frac{1-V_{\mathrm{F}}}{T_{\mathrm{F}}}\right)$,

where $\mathrm{P}_{\mathrm{P}}$ is the permeability of the pure polymer. Bourbigot et al. (Bourbigot et al. 2000) have demonstrated

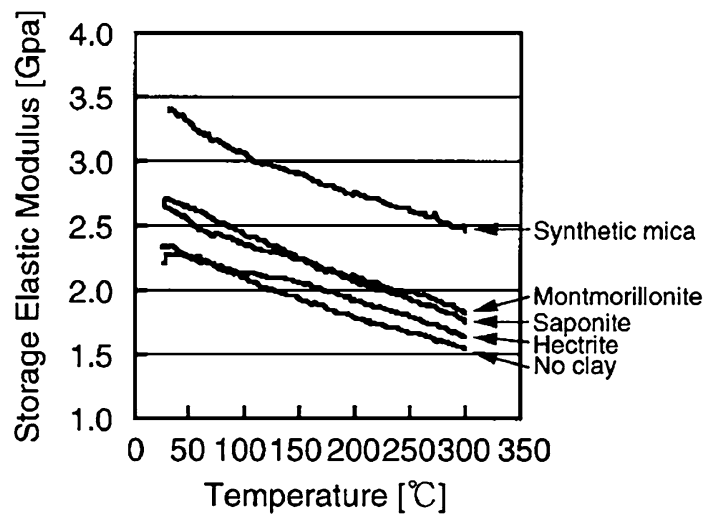

Fig. 2 Variation of storage elastic modulus with temperature of polyimide-based nanocomposites filled with $2 \mathrm{wt} \%$ of nanoclay (reproduced from (Yano et al. 1997) with the permission from John Wiley \& Sons Inc.) reduction in the permeability of gases like oxygen $\left(\mathrm{O}_{2}\right)$, water vapor $\left(\mathrm{H}_{2} \mathrm{O}\right)$, helium $(\mathrm{He})$, carbon dioxide $\left(\mathrm{CO}_{2}\right)$ and ethyl acetate vapor in clay-based nanocomposites. A $2 \mathrm{wt} \%$ clay loading decreases the water vapor permeability coefficient by 10 -fold. Figure 4 shows permeability of polyimide nanocomposites obtained with different types of fillers loaded by 2 wt\% (Yano et al. 1997). Reduction in permeability is higher in nanocomposites with fillers of higher length. Fully exfoliated LS give the lowest permeability due to their creation of longer diffusive path. Owing to these properties along with excellent abrasion and heat resistance, polyimide/clay nanocomposites are used as step assist in automobiles. In a similar way, polyimide/clay nanocomposites are suitable for floor lining in the cargo area of commercial airliners.

\section{Epoxy/clay and epoxy/CNT}

Processing of polymer/clay or polymer/CNT nanocomposites involves the dispersion of clay or CNT in epoxy resin using ultrasonication followed by curing in molds to form a structure. Ultrasonication continues for usually $30 \mathrm{~min}$ followed by curing for $24 \mathrm{~h}$. Curing is carried out at $70{ }^{\circ} \mathrm{C}$ to avoid damage to the nanostructures (Dinca et al. 2012).

Mechanical testing done on epoxy nanocomposites with clay or CNT fillers reveals an increased modulus of elasticity as shown in Table 1. Epoxy/CNT and epoxy/clay show better thermo-mechanical properties as compared to pristine matrix. $\mathrm{COOH}$-functionalized epoxy/multiwalled carbon nanotube (epoxy/MWCNT) has a tensile strength of 121.8 $\mathrm{MPa}$, whereas pure epoxy has a tensile strength of $95 \mathrm{MPa}$. Increase in CNT concentration increases the modulus of elasticity but decreases the tensile strength. Addition of nanoparticles is limited to $2 \%$ since rheological properties deteriorate above these levels.

Epoxy/clay can serve as attractive replacements for the expensive talc powder and $\mathrm{TiO}_{2}$ to attenuate the permeability in fuel tanks (Stan et al. 2011, Luan et al. 2012). Nanocomposites like fluoropoly(ether-amic acid)/montmorillonite (6F-PEAA/MMT) and polyethylene terephthalate/LS have also yielded significant improvement in mechanical properties, impact strength, barrier properties and flame properties (Vora and Vora 2006). These properties are highly desirable in providing safety to aerospace structures in the event of fire and impact. Toyota used polymer/clay nanocomposite for structural applications by modifying natural clays (Giannelis 1996). Nanostructured LS is a clay used to prevent gas diffusion through polymers. Thus, epoxy/clay nanocomposite is suitable for fabrication of extremely lightweight and strong cryogenic gas storage tanks for aerospace applications. These 
Fig. 3 Tortuous path in polymer/LS nanocomposite (reproduced from (Ray and Okamoto 2003) with the permission from Elsevier)
Conventional composites

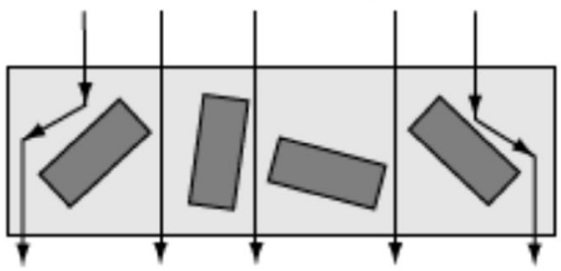

"Tortuous path" in LS nanocomposites

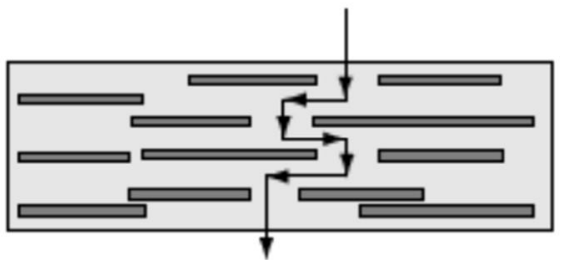

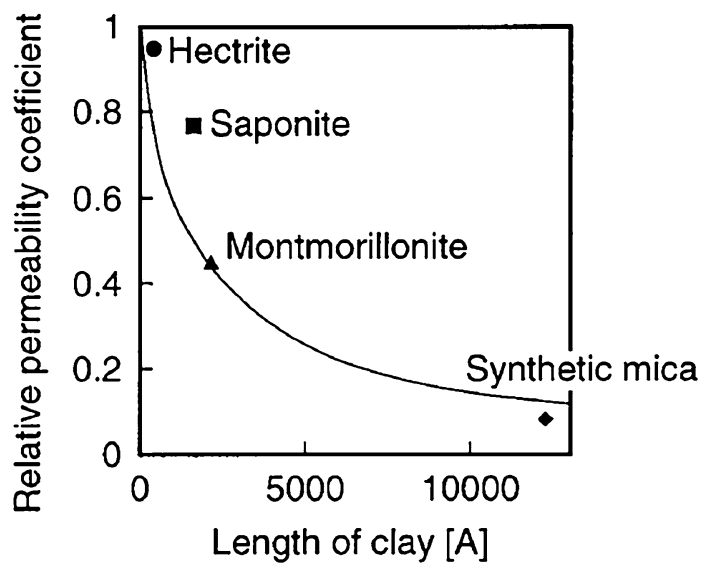

Fig. 4 Variation of relative permeability coefficient with clay length (reproduced from (Yano et al. 1997) with the permission from John Wiley \& Sons Inc.)

nanocomposites are also flame resistant (Gilman et al. 1977) which make them suitable for aerospace and space environments.

\section{Nylon-6/layered silicate (Nylon-6/LS)}

Nylon-6/LS like nylon-6/MMT is prepared by a process of in situ intercalative polymerization. This involves the melt mixing of LS with nylon matrix without the need of a solvent (Vaia et al. 1993; Vaia and Giannelis 1997). The LS is encased within liquid monomer to polymerize by the action of heat, radiation, diffusion, catalyst and exchange of cations between the layers (Usuki et al. 1993; Messersmith and Giannelis 1994). 2:1 phylosilicates is commonly used which has layer thickness of $1 \mathrm{~nm}$ made up of a sheet of alumina sandwiched between two silica sheets. Weak van der Waals interactions hold the layers together. Small molecules can be intercalated between these layers easily (Azeez et al. 2013). Isomorphic substitution in the interface produces negative charges counterbalanced by the alkaline cations. Cations also provide functional groups that can react with polymer matrix increasing the strength of the formed interface (Krishnamoorti et al. 1996). Montmorillonite $\left(\mathrm{M}_{\mathrm{x}}\left(\mathrm{Al}_{4-\mathrm{x}} \mathrm{Mg}_{\mathrm{x}}\right) \mathrm{Si}_{8} \mathrm{O}_{20}(\mathrm{OH})_{4}\right) \quad$ (MMT), hectorite $\left(\mathrm{M}_{\mathrm{x}}\left(\mathrm{Mg}_{6-\mathrm{x}} \mathrm{Li}_{\mathrm{x}}\right) \mathrm{Si}_{8} \mathrm{O}_{20}(\mathrm{OH})_{4}\right)$ and saponite $\left(\mathrm{M}_{\mathrm{x}} \mathrm{Mg}_{6}\left(\mathrm{Si}_{8-\mathrm{x}-}\right.\right.$ $\mathrm{Al}_{\mathrm{\gamma}} \mathrm{O}_{20}(\mathrm{OH})_{4}$ ) are the examples of commonly used LS, where hydrated cations are ion-exchanged with bulkier organic cations (Ray and Okamoto 2003). Montmorillonite imparts remarkable changes in thermal and mechanical properties of the nanocomposite. Incorporation of $4.1 \mathrm{wt} \%$ MMT in Nylon-6 matrix results in $102.7 \%$ increase in Young's modulus (Kojima et al. 1993). Figure 5 shows the variation of Young's modulus with clay content of an organo-modified nanocomposite (Kojima et al. 1993). Nylon-6/LS are used in timing belt cover of automotive engines (Bogue 2011). These nanocomposites additionally

Table 1 Mechanical properties of epoxy/clay and epoxy/CNT nanocomposites

\begin{tabular}{|c|c|c|c|c|c|}
\hline Nanocomposite & $\begin{array}{l}\text { Tensile strength } \\
\text { (MPa) }\end{array}$ & $\begin{array}{l}\text { Shore } \\
\text { hardness }\end{array}$ & $\begin{array}{l}\text { Thermal stability } \\
\left({ }^{\circ} \mathrm{C}\right)\end{array}$ & $\begin{array}{l}\text { Modulus of elasticity } \\
(\mathrm{GPa})\end{array}$ & References \\
\hline Epoxy & 95 & 75 & 50 & 2.8 & Dinca et al. (2012) \\
\hline Epoxy +2 wt $\% 30$ B & 102.5 & 83 & 56 & 3.1 & Dinca et al. (2012) \\
\hline Epoxy +2 wt $\%$ MWCNT & 98 & 77 & 55 & - & Dinca et al. (2012) \\
\hline $\begin{array}{l}\text { Epoxy }+2 \text { wt } \% \text { MWCNT- } \\
\text { COOH }\end{array}$ & 121.8 & 85 & 59 & 3.42 & Dinca et al. (2012) \\
\hline Epoxy & 52.5 & - & - & 2.52 & $\begin{array}{l}\text { Micheli et al. } \\
\text { (2011a) }\end{array}$ \\
\hline Epoxy +0.1 wt $\%$ MWCNT & 24.7 & - & - & 2.42 & $\begin{array}{l}\text { Micheli et al. } \\
\text { (2011a) }\end{array}$ \\
\hline Epoxy +0.5 wt $\%$ MWCNT & 29.5 & - & - & 2.97 & $\begin{array}{l}\text { Micheli et al. } \\
\text { (2011a) }\end{array}$ \\
\hline
\end{tabular}




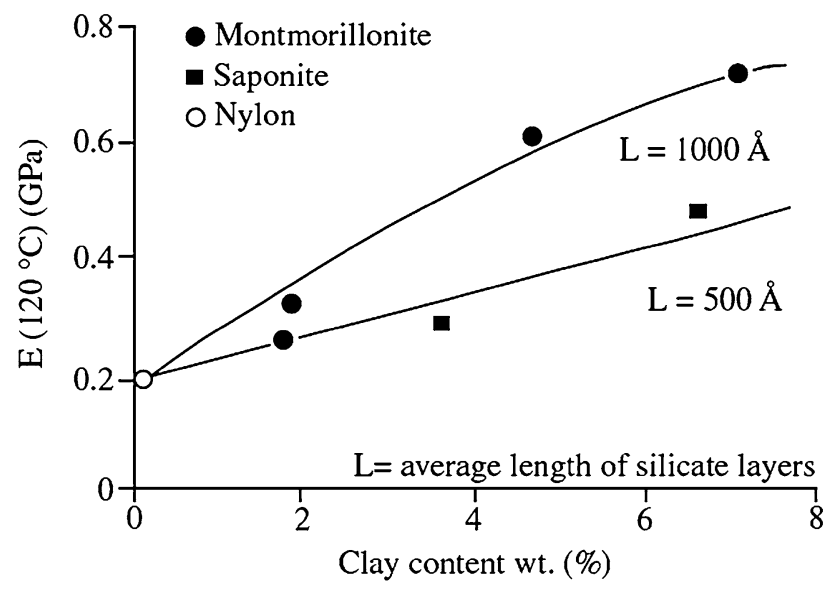

Fig. 5 Variation of Young's modulus at $120{ }^{\circ} \mathrm{C}$ on clay content with organo-modified LS (reproduced from (Kojima et al. 1993) with the permission from Materials Research Society)

possess an ablative property (Vaia et al. 1999) with which they have the potential for their use in aerospace engine components, body panels and crash guards.

\section{Epoxy/DOPO-based phosphorus tetraglycidyl}

High-performance materials possessing superior thermal and mechanical properties have seen rapid developments for aerospace applications involving adverse operating conditions. Epoxy resins have excellent properties like toughness, adhesion and chemical resistance. However, epoxy does not possess thermal and mechanical properties required by the aerospace structures. Phosphorus containing flame-retardant compounds like triphenyl phosphate requires high loading to achieve the desired flame retardation. Polyhedral oligomeric silsesquioxanes (POSS) reagents have appeared as alternative materials, which can be incorporated easily in a polymer matrix like acrylics, styryls, epoxy and polyethylene.

A high-performance 10-dihydro-9-xa-10-phosphaphenanthrene-10-oxide (DOPO)-based phosphorus tetraglycidyl epoxy nanocomposite has been proposed by Meenakshi et al. (Meenakshi et al. 2011) for aerospace structural applications due to its good mechanical, thermal, flame-retardant and water absorption properties. The nanoreinforcement POSS amine was mixed with the epoxy resin followed by curing process. The mechanical properties of such cured nanocomposites with resin types containing nanoclay and POSS amine as nanofillers are compared in Table 2. Bis (3-aminophenyl) phenylphosphine oxide (BAPPO) and diaminodiphenylmethane (DDM) were the curing agents used. The mechanical properties of the nanocomposites with POSS showed better mechanical properties even when compared to the prop- erties of clay-based nanocomposites. The reason was attributed to the small size of POSS that restricts the mobility of surrounding polymer chain and good interfacial adhesion. Flame-retardant tests showed enhancement in flame-retardant properties due to the protection of underlying matrix by char formation on surface and the low surface energy associated with the $\mathrm{Si}-\mathrm{O}-\mathrm{Si}$ present in POSS (Ni et al. 2004). Water absorption drastically reduces due to hydrophobic and partially ionic nature of $\mathrm{Si}-\mathrm{O}-\mathrm{Si}$ link (Haque et al. 2003). These exceptional mechanical, thermal, flame-retardant and water-barrier properties makes the polymer/POSS nanocomposite suitable for highperformance aerospace structures.

\section{Aerospace coating applications}

Aerospace structures are subjected to diverse environments that include variations in moisture and temperature. They are also subjected to the contact with jet fuel, deicing fluid and hydraulic fluid. The coatings should withstand lightning strikes, ultraviolet exposure and erosion from dust flowing at $500 \mathrm{mph}$. An aerospace coating typically has a primer and a topcoat. The primer provides the substrate with adhesion and protection from corrosion. The topcoat is required to have matte finish, flexibility, durability, chemical resistance, corrosion protection and stable color for good appearance (Blackford 1998). These requirements are classified as shown in Fig. 6. The conventional ways to meet such requirements are explained in brief next.

Lightening protection and electromagnetic shielding: Lightning strike can cause direct effects, indirect effects and damages in an aircraft. Direct effects and damages can be caused from heat $\left(\sim 30,000{ }^{\circ} \mathrm{C}\right)$, acoustic shock waves (500 psi impact force) and electrical charge ( 200,000 A current) (Rupke 2002). Indirect effect may cause damage or interruption of electronic equipment. Heat is generated by resistive or joule heating that causes most damage likely by the breakdown of matrix in composite. To prevent localized damage, thin metal mesh is embedded in outer layers of composite (Gagne and Therriault 2014). This also serves as a shield for electrical systems. Nonconductive composites are given protection by strips on exterior surface to intercept lightning allowing the transparency to electromagnetic waves emitted from the antennas (through composites panels of antenna fairings). When radio frequency transparency is not required, conductive material is applied over exterior surface. To improve electromagnetic interference (EMI) and lightning strike resistance, conductive resins and single-walled carbon nanotube Buckypaper materials were introduced in composite materials 
Table 2 Mechanical properties of epoxy/DOPO nanocomposites (reprinted from (Meenakshi et al. 2011), with the permission from Elsevier)

\begin{tabular}{lcllll}
\hline Resin system & $\begin{array}{l}\text { Tensile strength } \\
(\mathrm{MPa})\end{array}$ & $\begin{array}{l}\text { Tensile modulus } \\
(\mathrm{GPa})\end{array}$ & $\begin{array}{l}\text { Flexural strength } \\
(\mathrm{MPa})\end{array}$ & $\begin{array}{l}\text { Flexural modulus } \\
(\mathrm{GPa})\end{array}$ & $\begin{array}{l}\text { Impact strength } \\
\left(\mathrm{KJ} / \mathrm{M}^{2}\right)\end{array}$ \\
\hline TG-DOPO + DDM & 91 & 6.90 & 148 & 4.78 & 35 \\
TG-DOPO + 5\% clay-DDM & 77 & 7.00 & 157 & 4.88 & 31 \\
TG-DOPO + 5\% POSS-DDM & 104 & 7.13 & 165 & 4.95 & 27 \\
TG-DOPO + BAPPO & 97 & 6.98 & 154 & 4.84 & 27 \\
TG-DOPO + 5\% clay-BAPPO & 83 & 7.11 & 163 & 4.93 & 29 \\
TG-DOPO + 5\% POSS-BAPPO & 110 & 7.20 & 171 & 5.05 & 24 \\
\hline
\end{tabular}

Fig. 6 Requirements of aircraft structural coatings (Peng 2011)

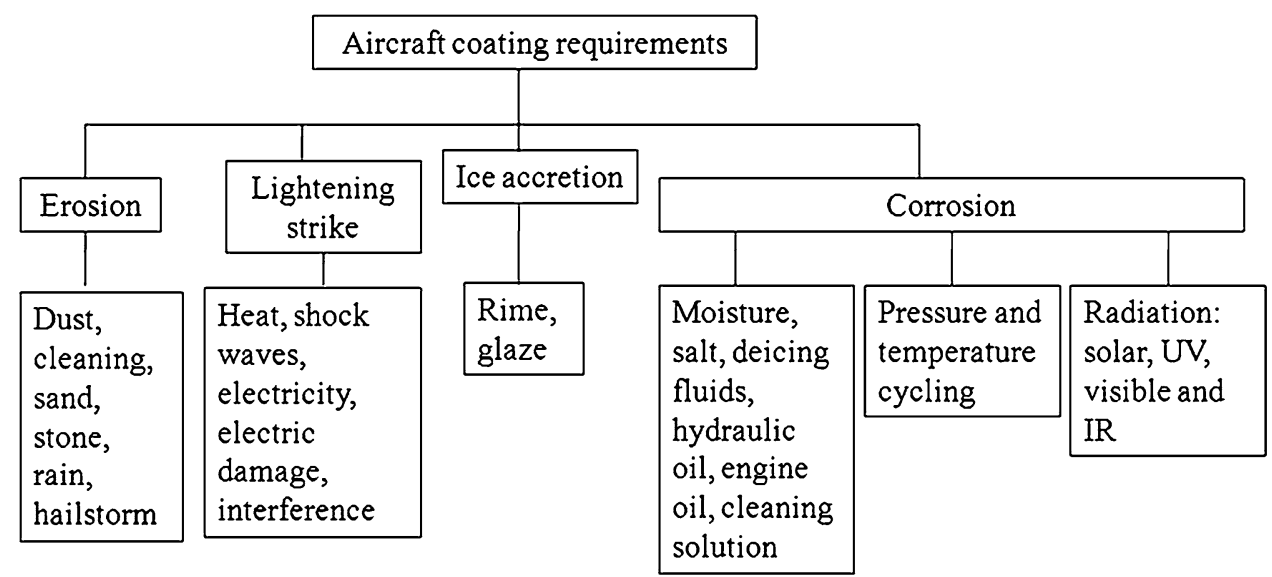

(Wang et al. 2005a; Gonnet et al. 2006; Park et al. 2009). These Bucky-paper materials consisted of highly loaded and magnetically aligned CNTs whose conductivity changed linearly with temperature.

Erosion: Erosion due to sand particles is higher at oblique incidence due to scrubbing, microcutting action and chip formation in ductile metal and polymers and due to cracking and brittle fracture in ceramics and brittle polymers (Lancaster 1990; Baikoula and Kirger-Kocsis 2002). Rain droplets cause impact induced debonding of coating from the surface causing fatigue and tearing (Lesser 1995). Rime and clear glaze of mixed ice (Armitage et al. 2004) can be rougher than a coarse sand paper during their peeling off from the aircraft skin causing erosion. Nickel, titanium shields, pure PU, blend of PU or polyethylene coatings are used conventionally for protection from erosion (Van Krevelen 1990).

Deicing and anti-icing: Deicing and anti-icing performed on aircrafts help to remove and prevent the formation of ice. A thermally insulating coating reduces the efficiency of deicing process carried out by electrical heaters. In addition, retaining of heat within the insulation degrades the composite structures (Peng 2011). Electric matrix, CNT paper-resist heaters and transparent MWNT films have been developed for deicing (Yoon et al. 2007). Whereas, to reduce ice adhesion, ice-phobic coatings like Rain-X and MP55 poly(tetrafluoroethylene) (PTFE) coatings have been developed (Ferrick et al. 2006).

Radiation and corrosion protection: Ultraviolet rays, humidity, heat and gas present in atmosphere cause corrosion. Galvanic corrosion also results from composite (anodic) and metal combinations (cathodic). Since corrosion is a primary mode of failure in aircrafts, coating is designed to provide corrosion protection. Coatings with low permeability for liquids give barrier protection. Inhibitive pigments added in the coatings impart electrochemical property and passive protection to provide sacrificial protection (Sorensen et al. 2009).

To achieve these requirements, two-component PU systems have been used (Bierwagen and Tallman 2001). Current aircraft coatings have limited life and capabilities. Polymer nanocomposites provide the flexibility to tune for mechanical, chemical, electrical, thermal, optical properties and their selective combinations for the aerospace coatings (Baer et al. 2003). Development of novel coatings to address the challenges of lightning, icing, erosion and corrosion is a focused area of research at present. 
Following subsections present the nanocomposite coatings and their specific aerospace applications.

\section{Conductive polymer/CNT for EMI shielding}

Nanocomposite coatings embedded with fillers of various functionalities suit for the topcoat of the aircrafts satisfying its multiple requirements. Polyurethane elastomers possess high wear resistance, corrosion resistance, elasticity and adhesive property (Howarth 2003; Chattopadhyay and Raju 2007). Fillers like clay, alumina, CNT and nanodiamond serve as main ingredients in the development of aerospace coatings (Peng 2011). Spray painting is a technique adapted for aircraft painting. Adding fillers increases the viscosity causing difficulty in spray painting along with inadequate wetting of nanoparticles and additives. Alternatively, electrospinning method is used to fire a jet of solution through capillary tube on the surface (Lyons and Ko 2005). The possibility of adding nanofibers and CNT in the solution can produce coatings with good flexibility, strength and area-to-volume ratio. The fabricated coatings for aerospace applications differ in composition depending upon the structural location and its corresponding functional requirements.

Conductive filler like SWNT as low as $0.5 \mathrm{wt} \%$ is sufficient to impart electrical conductivity for electrostatic dissipation and EMI shielding. Variation of electrical resistivity with SWNT content (wt \%) in a polycarbonate (PC) matrix is shown in Fig. 7 (Ramasubramaniam and Chen 2003). A drop of resistivity from $10^{13}$ to $10^{8}$ is seen by an addition of $0.5 \mathrm{wt} \%$ MWNTs. For an addition of 5

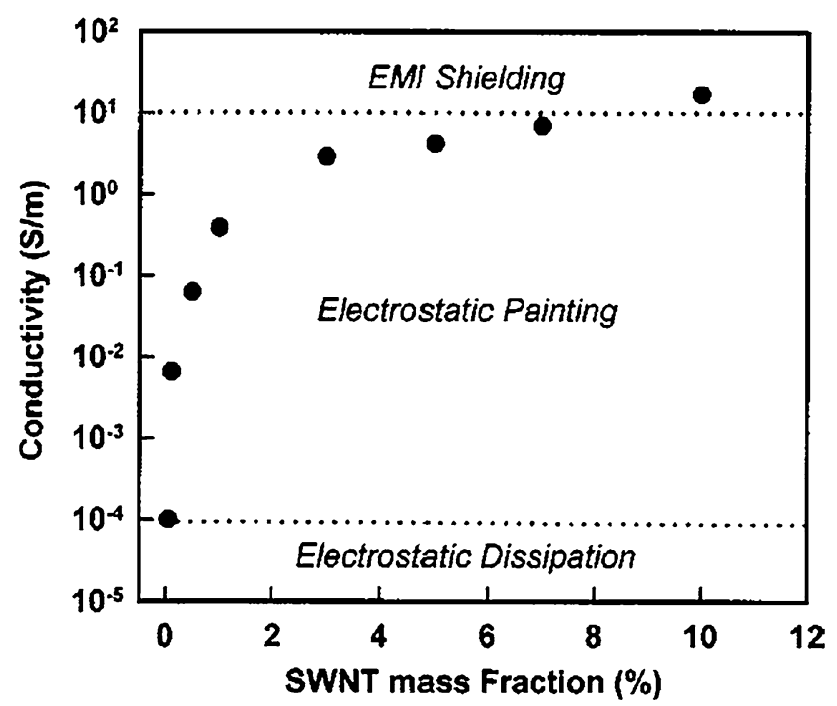

Fig. 7 Variation of electrical conductivity with SWNT loading of a PC/SWNT nanocomposite (dashed lines represent the lower limit/ percolation threshold) (reproduced from (Ramasubramaniam and Chen 2003), with the permission from American Institute of Physics) wt $\%$ MWNT, the resistivity further reduces to $10^{6}$. Resistivity at $0.5 \mathrm{wt} \%$ loading is sufficient to achieve the electrostatic discharge requirements (Xia and Song 2006). Such low loading of filler does not alter other physical properties of the coating. Aircrafts that are heavily equipped with electronic systems can seek protection from high-intensity radiated fields by sources in air or on land or sea (Peng 2011) by employing PC/SWNT nanocomposite coatings. In addition, the surface conductivity of PC/SWNT nanocomposite coatings also enhances the lightning strike protection.

\section{Conductive epoxy/CNT heaters for deicing}

Ice accretion occurs on an aircraft flying between 3000 and $5000 \mathrm{ft}$, consequently increasing the weight and drag. Ice accumulation significantly alters the stall speed, which is risky (Gent et al. 2000; Zeppetelli and Habashi 2012). To mitigate ice accumulation, ice protection systems (IPS) in aircrafts use the air bleed from engines, which are not economical. Electromechanical deicing using ultrasonic exciters and electromagnets causes aircraft skin fatigue and noise. Electric heaters are widely used to prevent icing with greater efficiency. These solutions available today have limitations of weight, power, maintenance and integration within the structure. Thin-film nanocomposite heating element $(0.038 \mathrm{~mm})$ has been developed which is strong and flexible (Buschhorn et al. 2013, Brampton et al. 2014). These heaters have negligible weight, consume low power, are maintenance free and can be easily integrated within the structure. The heater patch consisted of $\sim 100 \mu \mathrm{m}$ tall CNT arrays synthesized by a thermal catalytic chemical vapor deposition process (Bradford et al. 2010). The CNT array was densified to a film by pushing them in one direction using a steel tool of small radius. The film and its morphology are shown in Fig. 8. The films were integrated on a bistable composite laminate and on an aero-surface substrate using for testing. The dominant charge transport mechanism in such films is tunneling, which causes heating (Li et al. 2007).

The voltage was applied across the heater on a bistable laminate, and the current was measured across it. A linear relation between voltage and current was seen above $0.1 \mathrm{~A}$, where the resistance stayed constant. At 0.63 $\mathrm{A}$ and $5 \mathrm{~V}$, the bistable laminate snapped due to the rise in temperature. However, due to heating, the resistance did not change indicating the thermal stability of the nanocomposite heater. The snapping of the laminate causes the curvature to change rapidly causing the ice to shear off from the surface especially during a cold start. The heating and snapping of the wing surface ensure the freedom from ice buildup. The power $P_{\mathrm{H}}$ required by thin-film heater drawing current $I_{\mathrm{H}}$ is inversely proportional to thickness as 


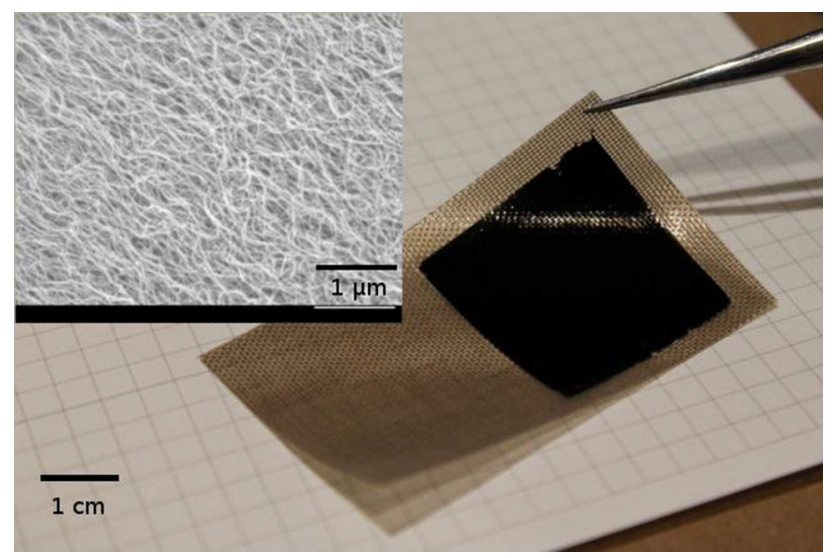

Fig. 8 Image from scanning electron microscopy (SEM) showing the morphology of densified CNT film and an optical image of a small film on a Teflon sheet (images courtesy of MIT necstlab, MIT (c) 201x (Buschhorn et al. 2013))

$P_{\mathrm{H}}=\frac{I_{\mathrm{H}}^{2} R_{\mathrm{H}} L_{\mathrm{H}}}{w_{\mathrm{H}} h_{\mathrm{H}}}$,

where $R_{\mathrm{H}}, L_{\mathrm{H}}, w_{\mathrm{H}}$, and $h_{\mathrm{H}}$ are the resistivity, length, width and thickness of the element. High electrical conductivity and low thickness allow the heater to heat itself and the substrate quickly. A linear relationship between power and temperature (of the heater and laminate) was seen above $0.1 \mathrm{~W}$ of power. Thus, deicing temperature can be controlled by controlling the power of the nanocomposite heater. Ice tunnel test was performed on wings with nanocomposite heaters embedded on the skin (Buschhorn et al. 2013). Harsh environment was created with temperature from 20.9 to $-3.9{ }^{\circ} \mathrm{C}$, with an airspeed of $\sim 55.9 \mathrm{~m} / \mathrm{s}$ and water content of $1.1 \mathrm{~g} / \mathrm{m}^{3}$ with mean volume droplet size of $30 \mu \mathrm{m}$. Nanocomposite heaters demonstrated successful deicing capability (see Fig. 9) as required by aircrafts flying through snow and storm.

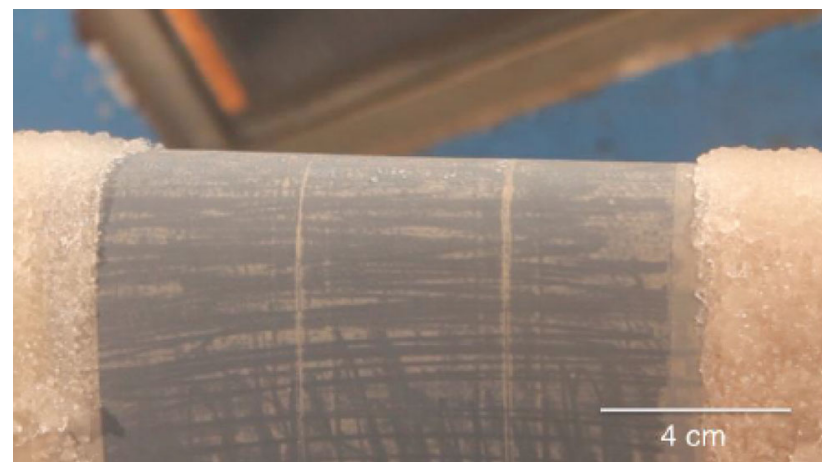

Fig. 9 Aerosurface showing deicing during an IPS testing in ice tunnel (image courtesy of MIT necstlab, MIT (C) 201x (Buschhorn et al. 2013))

\section{Scratch-resistant epoxy/clay and epoxy/alumina}

Epoxy coatings are low-cost coatings exhibiting good hardness, adhesion, chemical resistance and corrosion resistance. Turri et al. (Turri et al. 2010) developed nanostructured coatings made of epoxy/clay and epoxy/ alumina having additional properties like greater scratch strength, thermal properties and barrier properties, fulfilling major requirements of aerospace coatings. Fabrication of these coatings involves the mixing of resin and nanoparticles at $40{ }^{\circ} \mathrm{C}$ for $30 \mathrm{~min}$. Nano- $\mathrm{Al}_{2} \mathrm{O}_{3}$ (AluC) and cloisite 30B, organophilic MMT clay (CL30B) fillers were added to prepare two different types of nanocomposites. Hardener was added to the mixture, and the resulting mixture was bar coated on a glass substrate followed by curing consecutively at ambient temperature, at $50{ }^{\circ} \mathrm{C}$ and at $120^{\circ} \mathrm{C}$, for $2 \mathrm{~h}$ at each temperature level to get a coating of $200-400 \mu \mathrm{m}$. Self-cross-linked hybrid coatings were prepared by mixing 5\% silica in a silanized epoxy. Silanized epoxy was prepared by blending diglycidyl ether of bisphenol A and 3-aminopropyltriethoxysilane in 1:2 molar ratio for $2 \mathrm{~h}$ in nitrogen atmosphere. This mixture was added in a sol containing tetraethyl orthosilicate, water and ethanol at a molar ratio of 1:3:4.5 and gently stirred. Similarly, epoxy/ $/ \mathrm{Al}_{2} \mathrm{O}_{3}$ coatings were also prepared.

Atomic force microscopy (AFM) topography and demodulation images were obtained to study the surface roughness and scratch hardness. The surface topography was obtained from the mean surface roughness and rootmean-square values. A demodulation phase image for the hybrid epoxy/SiO${ }_{2}$ nanocomposite is shown in Fig. 10. The roughness was estimated from median surface level and standard deviation within the image. The small domains

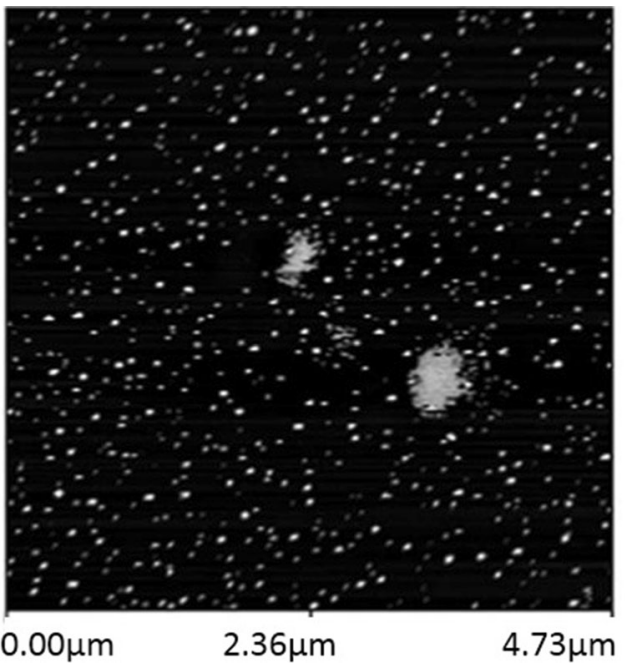

$3715.88 \mathrm{mv}$

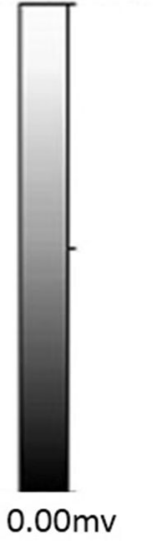

Fig. 10 Phase image of epoxy/SiO $\mathrm{S}_{2}$ nanocomposite coating (reproduced from (Turri et al. 2010), with the permission from Wiley Periodicals Inc.) 
indicated by bright spots are the hard phase, and dark zones are the soft polymer matrix. Phase separation is not seen in the image, and silica particles were fully embedded in the polymer matrix.

Topographic images obtained after making a nanometric scratch on epoxy/clay and on hybrid epoxy/SiO${ }_{2}$ coating are shown in Fig. 11a, b, respectively. A constant force of $F_{\mathrm{AFM}}=3400 \mathrm{nN}$ was applied on the AFM tip. Pileup was observed at the scratch location from which the width of the scratch was measured. Scratch hardness $H_{S}$ is given in terms of normal load $F_{\mathrm{AFM}}$ applied on the tip of AFM and width of the scratch $W_{\mathrm{S}}$ as (Briscoe et al. 1996; Williams 1996)

$H_{\mathrm{S}}=\frac{4 F_{\mathrm{AFM}}}{\pi W_{\mathrm{S}}^{2}}$

Standard tests like the Buchholtz indentation (for indentation hardness) and Taber tests (for wear resistance) were conducted. The indentation hardness

(a)

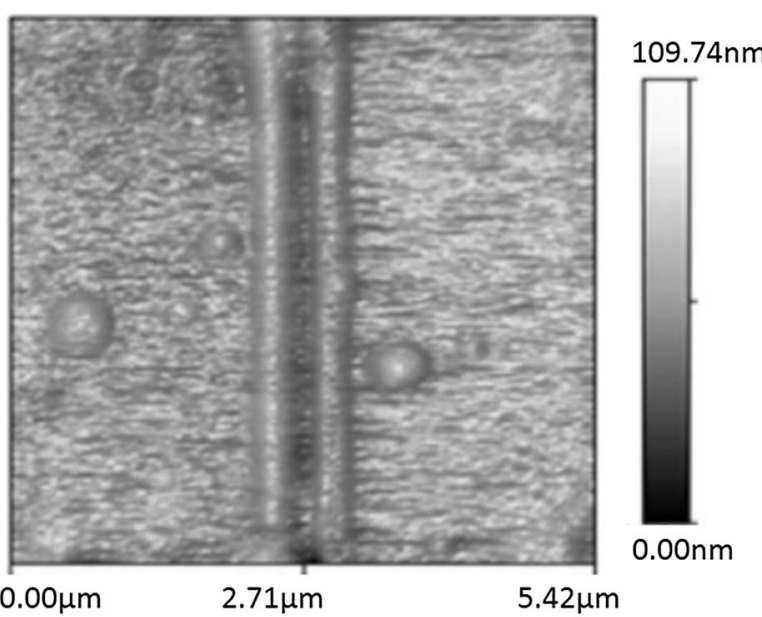

(b)

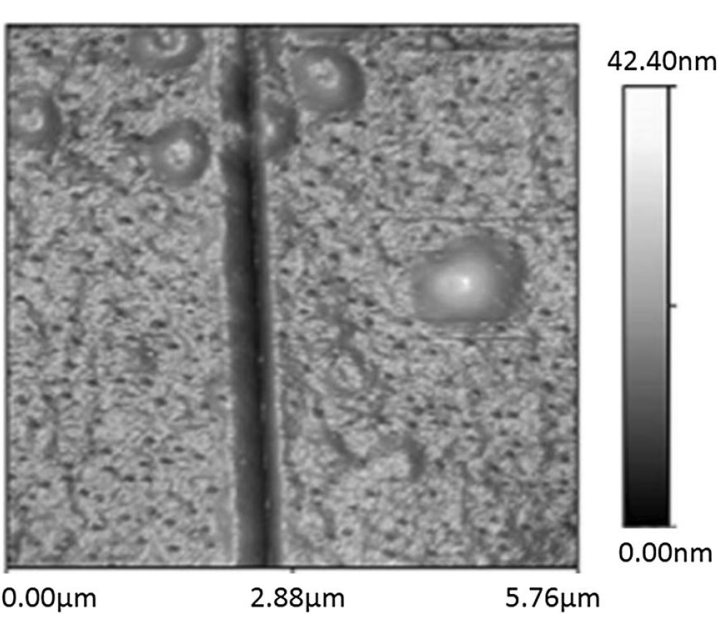

Fig. 11 Topographic images of: a epoxy/clay nanocomposite coating and $\mathbf{b}$ hybrid epoxy/SiO $\mathrm{S}_{2}$ nanocomposite coating (Reproduced from (Turri et al. 2010), with the permission from Wiley Periodicals Inc.) (evaluated from Eq. (4)) and wear resistance estimated for various types of coatings are given in Table 3. Alumina and clay-based nanocomposites showed improvement in indentation and scratch hardness when compared to a pristine epoxy. However, there was considerable increase in surface mean roughness of epoxy/clay nanocomposite. The wear index was improved in case of epoxy/alumina and decreased in case of epoxy/clay. Thus, epoxy/alumina coating is better than the epoxy/clay coating. The hybrid epoxy/ $\mathrm{SiO}_{2}$ coatings showed a remarkable improvement in scratch hardness maintaining the surface roughness below that of epoxy/clay coatings. Very high improvement in scratch hardness of 1830, 942 and $700 \%$ was seen in hybrid epoxy $/ \mathrm{SiO}_{2}$ coatings when compared to pristine epoxy, epoxy/alumina and epoxy/clay coatings, respectively. Thus, hybrid epoxy/SiO $\mathrm{S}_{2}$ coatings can be proposed as coatings for aircrafts operating in dusty conditions, sandstorms and hailstorms.

\section{Hydrophobic PVDF/MWCNT}

Superhydrophobic coatings have anti-sticking, anti-icing, self-cleaning and anti-corrosion properties, which can provide fluidic drag reduction and water corrosion prevention to the aerospace structures (Blossey 2003; Mishchenko et al. 2010; Hsu et al. 2013). Key parameters governing hydrophobicity are the nanoroughness and surface energy. Wenzel model describes an increased surface roughness leading to increased surface area imparting hydrophobic nature (Wenzel 1936), whereas the CassieBaxter model states that the air trapped within the grooves causes hydrophobic behavior (Cassie and Baxter 1944). Poly(vinilidene fluoride) PVDF is a strong polymer having properties like abrasion resistance and corrosion resistance.

Addition of CNTs imparts additional properties to the PVDF like hydrophobicity and conductivity (for EMI shielding and lightning protection) making the PVDF/CNT nanocomposites a suitable material for aerospace coatings. PVDF/CNT nanocomposites coatings were prepared by Chakradhar et al. (Chakradhar et al. 2014) using spray coating method. PVDF and MWCNTs were dispersed in dimethyl formamide (DMF) using a magnetic stirrer for $10 \mathrm{~min}$, followed by ultrasonication for $50 \mathrm{~min}$. The mixture was mixed with Milli Q water resulting in a precipitate. Precipitate was collected on a filter paper and dried. The dried powder was dissolved with acetone by ultrasonication for $30 \mathrm{~min}$. The mixture was sprayed on a glass substrate to form 10-12 $\mu \mathrm{m}$ thick coatings.

Surface morphology of coating with $66 \mathrm{wt} \%$ MWCNT examined by field electron scanning electron microscopy (FESEM) is shown in Fig. 12a. Protrusion-like structures were seen which cause enhanced surface roughness leading to reduced wettability as per the Cassie-Baxter's law. The 
Table 3 Properties of various epoxy nanocomposite coatings (Turri et al. 2010)

\begin{tabular}{llccc}
\hline Coating type & Mean surface roughness $(\mathrm{nm})$ & Indentation hardness & Wear index $(\mathrm{mg} / \mathrm{kcycle})$ & Scratch hardness $(\mathrm{MPa})$ \\
\hline Epoxy & $0.16 \pm 0.02$ & $99 \pm 2$ & $63 \pm 15$ & $42.8 \pm 3.2$ \\
Epoxy/alumina & $0.59 \pm 0.04$ & $101 \pm 7$ & $75 \pm 13$ & $83.1 \pm 3.1$ \\
Epoxy/clay & $3.15 \pm 0.04$ & $98 \pm 3$ & $33 \pm 5$ & $112.3 \pm 5.6$ \\
Hybrid Epoxy/SiO & $2.65 \pm 0.09$ & $87 \pm 11$ & $35 \pm 7$ & $783.6 \pm 51.6$ \\
\hline
\end{tabular}

PVDF/MWCNT coatings exhibit superphobicity in contact with the water (see Fig. 12b). The water contact angle (WCA) and sliding angle (SA) were found to be $154^{\circ}$ and $<3^{\circ}$, respectively (superhydrophobic), as compared to the WCA of PVDF which is $105^{\circ}$ (hydrophobic). The nanoroughness of the coating increased with the addition of MWCNT causing superhydrophobicity. WCA measured at different temperatures is shown in Fig. 13. For 20-30 wt $\%$ coatings, the WCA gradually reduced reaching $10^{\circ}$ at $623 \mathrm{~K}$. The 33-66 wt\% coatings showed considerable stability up to $573 \mathrm{~K}$. Thus, $33 \mathrm{wt} \%$ of MWCNT in the PVDF imparted the necessary superhydrophobicity to the coatings maintaining additional properties of the PVDF. These properties make the PVDF/MWCNT coatings suitable for aerospace coatings for wet climates.

\section{Aerospace tribology}

Addition of lubricating and reinforcing fillers imparts tribological properties to the nanocomposites. Lubricating microfillers like graphite, PTFE, molybdenum disulfide $\left(\mathrm{MoS}_{2}\right)$ decrease the friction of the sliding surfaces, but their weaker bond in the material reduces the strength. Reinforcing microfillers like glass and carbon fibers increases the strength but also increases the abrasiveness. Nanofillers overcome the drawbacks of these microreinforcements by the improvements in some characteristics of the nanocomposites (Dasari et al. 2009). Nanofillers

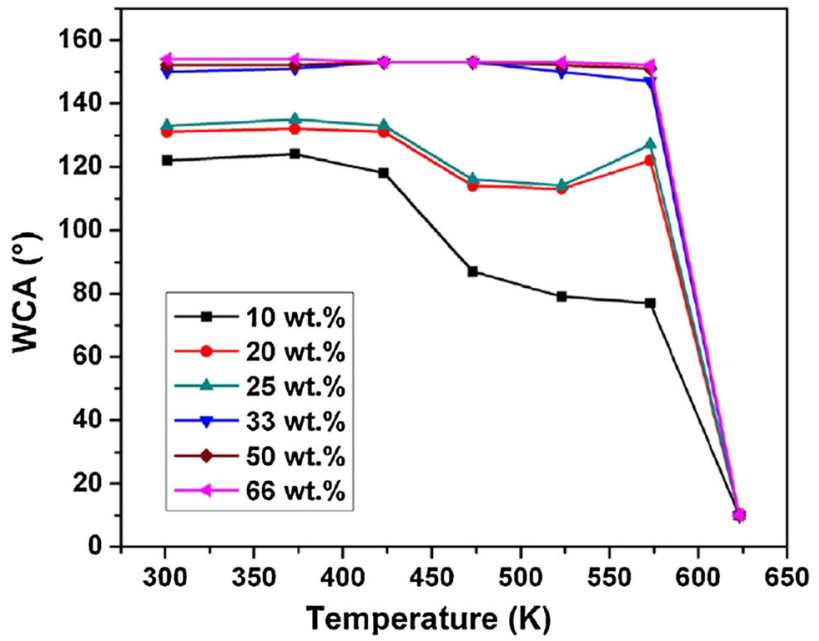

Fig. 13 Variation of WCA with temperatures in PVDF/MWCNT coatings (reproduced from (Chakradhar et al. 2014), with the permission from Elsevier)

increase the nucleation capability by improving interfacial interaction with the polymer matrix. Rigidity of the matrix is increased due to restricted mobility of the matrix occurring near vicinity of the fillers. Nanofillers are more effective than microfillers due to the increased surface area of fillers (Wetzel et al. 2003) that creates huge polymer/filler interfacial area resulting in enhanced bonding (Wetzel et al. 2003; Zhang et al. 2002). In addition,
Fig. 12 a Field electron scanning electron microscopy (FESEM) image of a PVDF/ MWCNT coating with $66 \mathrm{wt} \%$ MWCNT at room temperature. b Water droplets on a PVDF/ MWCNT superhydrophobic coating at $300 \mathrm{~K}$ (Reproduced from (Chakradhar et al. 2014), with the permission from Elsevier) (a)

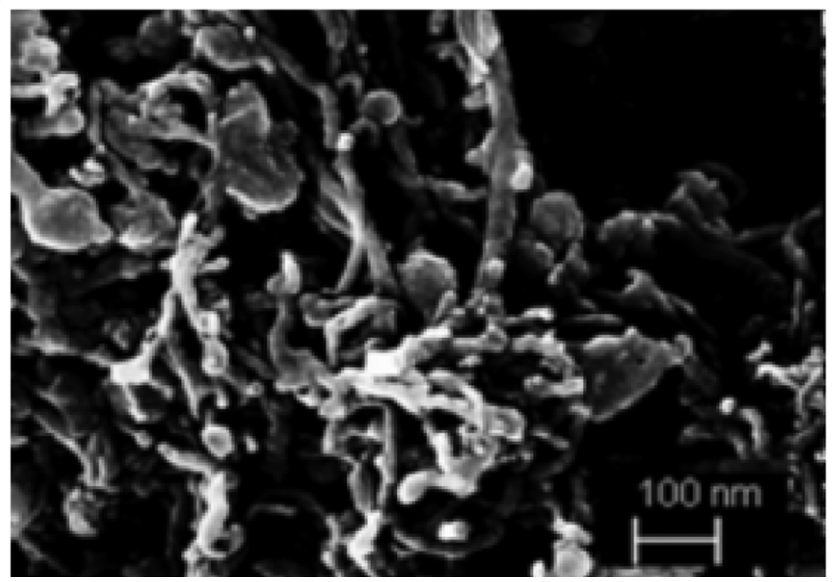

(b)

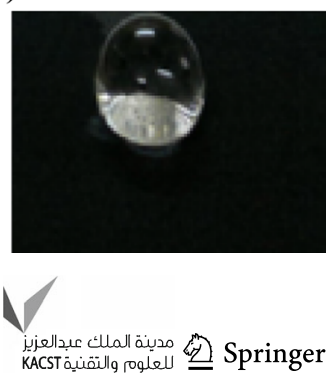


material removal during sliding is less since the size of nanofiller and surrounding polymer chain is similar.

Apart from changing the physical and mechanical properties, nanofillers change the crystallinity, microstructure, glass transition temperature and degradation temperature (Friedrich 1993). Nanofillers influence the transfer films, which is crucial in minimizing the wear rate in bearings. Wear results from the rubbing bodies due to friction, impact, thermal and other forces (Lim and Ashby 1987). Debris dislodge from the surface due to the loss of cohesion causing wear mechanisms like abrasion, adhesion, erosion, delamination, corrosion and fatigue. These mechanism involves softening, melting and pyrolysis making wear phenomenon more complex to understand. A widely accepted relation to estimate the wear volume loss $V\left(\mathrm{~m}^{3}\right)$ is given by

$V=\frac{k_{\mathrm{W}} \mathrm{NL}}{H}$,

where $k_{\mathrm{W}}$ is the wear coefficient $\left(\mathrm{mm}^{3} / \mathrm{N}-\mathrm{m}\right), N$ normal load $(N) ; l$ sliding distance $(\mathrm{m})$; and $H$ hardness of the wearing material. An important factor governing wear is the tribochemical reaction. Thus, Gibbs free energy $(\Delta G)$ criterion facilitates the selection of fillers (Zhao and Bahadur 1999). A negative $\Delta G$ indicates feasibility of a chemical reaction that helps on the formation of tribofilm reducing wear and favoring them for tribological applications.

Shao et al. (Shao et al. 2004) found that the frictional coefficient and wear rate decreased rapidly (Fig. 14) when $1 \mathrm{vol} \%$ nano- $\mathrm{TiO}_{2}$ particles were added to PPESK copolymer. Nanocomposite was slided over a steel ring in dry condition with velocity $=0.43 \mathrm{~m} / \mathrm{s}, \operatorname{load}=200 \mathrm{~N}$ and duration $=1.5 \mathrm{~h}$. Micro- $\mathrm{TiO}_{2}$ particles had negligible effect on friction coefficient and resulted in the increasing wear rate with increasing filler content. A continuous thin transfer film well bonded to the surface decreased the wear rate. A thin $\mathrm{Fe}_{2} \mathrm{O}_{3}$ film was formed, and the elemental $\mathrm{Ti}$ got attracted toward the steel surface bonding the formed film to the surface. Compared to the transfer film of pure PTFE (see scanning electron microscopy (SEM) image in Fig. 15), PTFE nanocomposites showed the smooth and coherent transfer films (Shi et al. 2007). Increasing the filler content increased the abrasiveness thereby increasing the wear rate. $\mathrm{Si}_{3} \mathrm{~N}_{4}$ also exhibited hydrodynamic lubrication behavior due to tribochemical wear when used in thermoplastic or thermosetting polymer (Shi et al. 2003; Wang et al. 1996). A formation of $\mathrm{SiO}_{2}$ in the tribofilm reduced the friction and protected the sliding surfaces. Table 4 lists the tribological properties of some nanocomposites. The lowest wear rate was exhibited by polyimide/CNT nanocomposite. These PMNCs are lightweight, have low friction and have low wear rate. In (a)

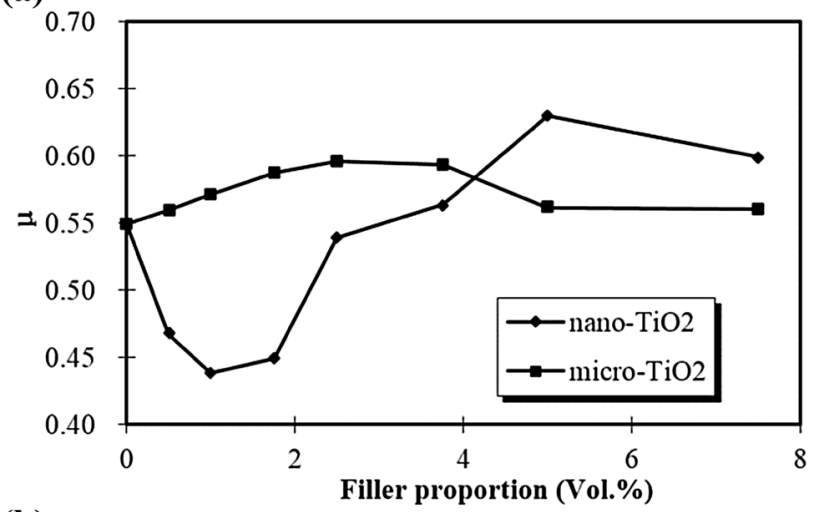

(b)

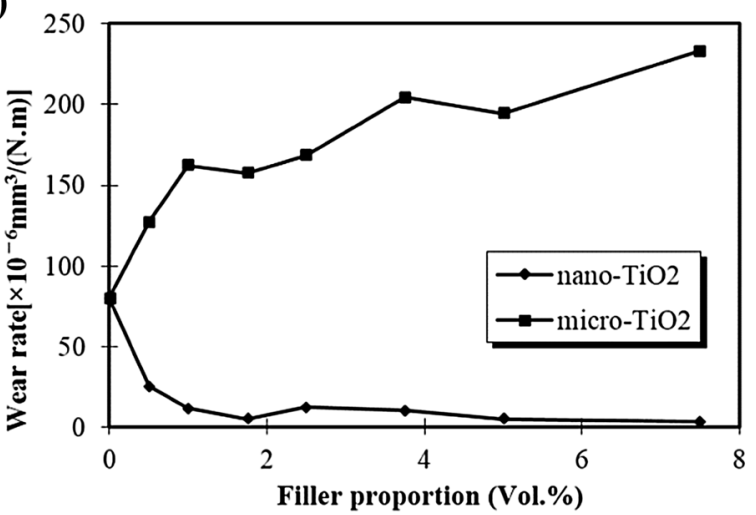

Fig. 14 Variation in properties of nano- and micro- $\mathrm{TiO}_{2}$-reinforced PPESK with different filler volume proportions: a coefficient of friction and $\mathbf{b}$ wear rate (reproduced from (Shao et al. 2004), with the permission from John Wiley and Sons)

addition, fillers like CNT impart thermal conductivity to remove the heat built up during operation. Thus, PMNCs are the preferred materials for the aerospace bearing design.

\section{Structural health monitoring applications}

Structural health monitoring (SHM) systems increase the reliability and safety of structures, which is mandatory for many critical and high-performance structures of aircrafts. SHM systems have reduced the cost involved by periodic inspection, which happens to be around one-third of the total cost in acquiring and operating the aircrafts (Diamanti and Soutis 2010; Giurgiutiu and Soutis 2012). Piezoelectric and piezoresistive nanocomposite sensors and actuators have been developed recently that are easy to fabricate, have low cost, making them suitable for the use in SHM systems of large aircrafts and various measuring gauges.

\section{Piezoelectric polymer matrix nanocomposites}

Piezoelectric PZT wafers are the widely used transducer elements in SHM (Rathod and Mahapatra 2010; Giridhara 
Fig. 15 Micrographs showing scanning electron microscopy (SEM) images of transfer films, a pure PTFE and b $17 \mathrm{wt} \%$ $\mathrm{TiO}_{2}$ particles in PTFE. Results obtained were with load of $200 \mathrm{~N}$, sliding velocity of $1.39 \mathrm{~m} / \mathrm{s}$, sliding time $=30 \mathrm{~min}$, sliding distance $=2.5 \mathrm{~km}$ (reprinted from (Shi et al. 2007), with the permission from Elsevier)
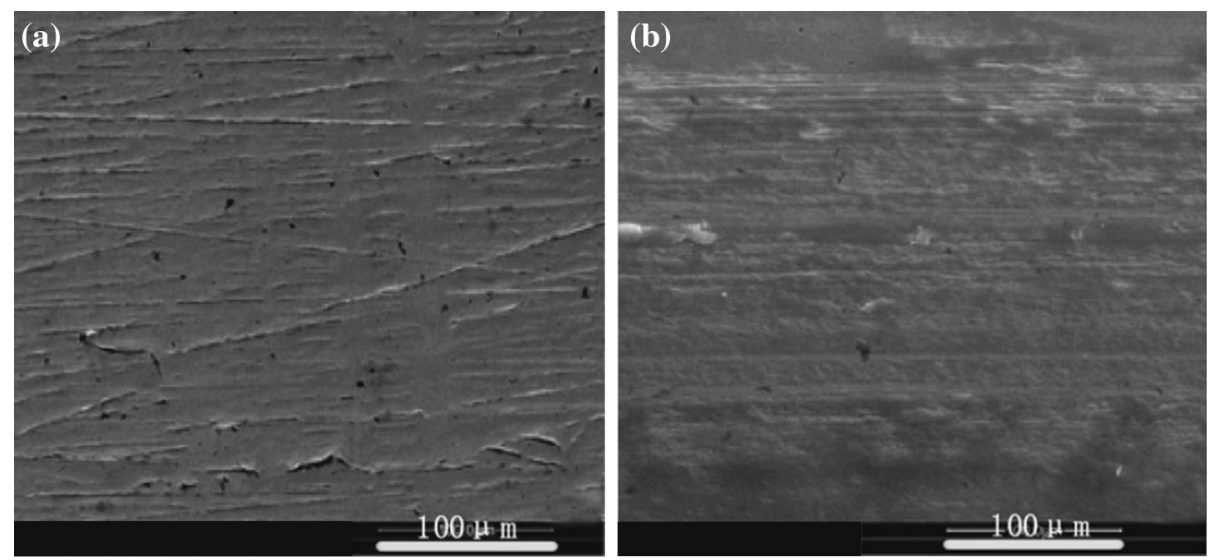

Table 4 Tribological properties of some polymer nanocomposites (Dasari et al. 2009; Friedrich et al. 2005)

\begin{tabular}{|c|c|c|c|c|}
\hline Material systems & Wear rate $\left(10^{-6} \mathrm{~mm}^{3} / \mathrm{km}\right)$ & Toughness $\left(\mathrm{kJ} / \mathrm{m}^{2}\right)$ & Hardness (MPa) & References \\
\hline Epoxy & 38 & 9.3 & 19 & Shi et al. (2003) \\
\hline Epoxy $/ 4$ vol\% $\mathrm{TiO}_{2}$ & 15 & 46 & - & Wetzel et al. (2002) \\
\hline Epoxy/0.9 vol\% nano- $\mathrm{Si}_{3} \mathrm{~N}_{4}$ & 7 & 13.2 & 20 & Dasari et al. (2009) \\
\hline Epoxy/2 vol\% $\mathrm{Al}_{2} \mathrm{O}_{3}$ & 3.9 & 55 & - & Wetzel et al. (2003) \\
\hline Epoxy $/ 3$ vol $\% \mathrm{SiO}_{2}$ & 22 & - & 208 & Sreekala and Eger (2005) \\
\hline Polyimide/10 wt $\%$ CNT & 0.1 & - & 380 & Dasari et al. (2009) \\
\hline Polyimide/10 wt $\%$ graphite & 0.7 & - & 300 & Dasari et al. (2009) \\
\hline PEEK/7.5 wt $\% \mathrm{Si}_{3} \mathrm{~N}_{4}$ & 1.3 & - & 133 & Wang et al. (1996) \\
\hline PEEK/7.5 wt $\% \mathrm{SiO}_{2}$ & 1.4 & - & - & Wang et al. (1997b) \\
\hline $\mathrm{PEEK} / 2.5 \mathrm{wt} \% \mathrm{SiC}$ & 3.4 & - & - & Wang et al. (1997a) \\
\hline $\mathrm{PEEK} / 10 \mathrm{wt} \% \mathrm{ZrO}_{2}$ & 3.9 & - & - & Wang et al. (1998) \\
\hline $\mathrm{PPS} / 5$ vol $\% \mathrm{TiO}_{2}$ & 8 & - & - & Bahadur and Sunkara (2005) \\
\hline $\mathrm{PTFE} / \mathrm{A}_{12} \mathrm{O}_{3}$ & 1.2 & - & - & Sawyer et al. (2003) \\
\hline
\end{tabular}

et al. 2010; Rathod and Mahapatra 2011; Giurgiutiu 2014). Due to their toxic nature, brittleness and high cost, piezopolymer transducers like PVDF and poly(vinylidene fluoride-trifluoroethylene) (P(VDF-TrFE)) have been developed as alternatives (Rathod et al. 2010; Jain et al. 2013a; Jain et al. 2013b). To facilitate the processing, piezoelectric PMNCs have been developed (Jain et al. 2014; Rathod et al. 2014). Nanocomposites also possess structural and electrical properties that can be tailored by controlling its composition to make them suitable for transducer applications. Piezoelectric PMNC consists of piezoelectric nanofillers like PZT, zinc oxide $(\mathrm{ZnO})$ embedded in a polymer matrix (Daben 1990; Jain et al. 2014; van den Ende et al. 2007; Meyers et al. 2013). These nanofillers impart piezoelectricity simultaneously retaining the properties of the polymer. Recently, PVDF and epoxy polymers have received close attention as matrix material, as discussed next.
PVDF/PZT films PVDF/PZT films exhibit piezoelectricity due to both PZT nanoparticles and the PVDF matrix. It also possesses the properties of PVDF like low acoustic impedance, strength, corrosion resistance, flexibility, nontoxic nature satisfying most of the requirements for aerospace sensor applications. Jain et al. (2014) have developed piezoelectric PVDF-PZT nanocomposite film sensors using a solvent cast method. A measured quantity of PVDF was dissolved in DMF by stirring and heating in the microwave oven until it dissolves. The PZT was dispersed thoroughly in the polymer PVDF solution. The average grain size of the PZT particles was in the range of $1 \mu \mathrm{m}$ to $25 \mu \mathrm{m}$. The prepared solution was then casted on the glass plate and heated in an oven at about $65^{\circ} \mathrm{C}$. With the complete evaporation of solvent, PVDF-PZT nanocomposite films were obtained. The process was repeated with different weight fractions (ranging from 10 to $50 \mathrm{wt} \%$ ) and different particle sizes of PZT. The prepared films were tested for 
structural, surface and mechanical properties by X-ray diffraction (XRD), SEM and tensile testing techniques, respectively. The graph in Fig. 16a presents the X-ray pattern of the film. It is clear from the patterns that most intense reflection occurs at $2 \theta-30.98^{\circ}$, which is very close to the value mentioned in the literature (Daben 1990) for PVDF-PZT nanocomposite. The intensity of (110) reflection increases as the PZT concentration increases from 10 to $50 \mathrm{wt} \%$. In addition, with the increase in size of PZT particle, the pattern remains same. This indicates that although the particle size of PZT is varied, the crystallite size remains same.
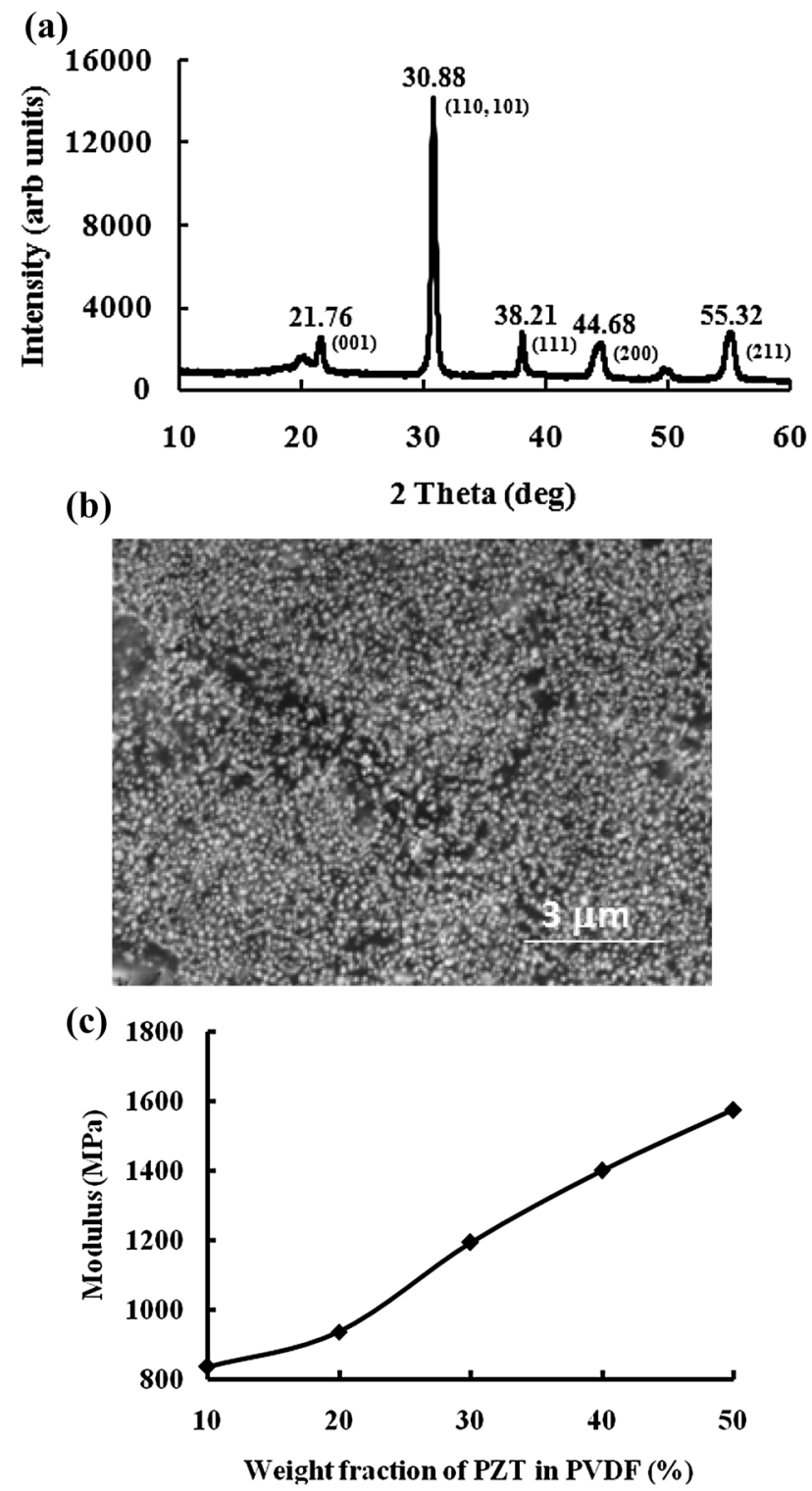

Fig. 16 Material characterization of PVDF-PZT nanocomposite film: a XRD pattern, b SEM, $\mathbf{c}$ variation in modulus with weight fraction of PZT
In order to study the microstructure and the dispersion of the ceramic powder within the polymer matrix, SEM was performed. A uniform distribution of PZT particles in the PVDF matrix is seen (see Fig. 16b) which has been observed by other investigators (Mendes et al. 2009; Suresh et al. 2009). From Fig. 16c, it has been found that the modulus increases with an increase in PZT content. At 50 wt $\%$ of PZT, modulus is found to be $1574 \mathrm{MPa}$. The increase in modulus and degree of crystallinity (discussed earlier) improves the piezoelectric properties (Mendes et al. 2009). After synthesis, the PVDF-PZT composite films were electroded using silver ink and were poled using thermal and corona poling method by the application of high direct current (DC) electric field $(9 \mathrm{kV} / \mathrm{mm})$ at an elevated temperature. Piezoelectric coefficients have been measured using a Piezometer PM300. The average value of piezoelectric charge coefficient $d_{33}$ obtained is $40 \mathrm{pC} / \mathrm{N}$, and the maximum value obtained is $100 \mathrm{pC} / \mathrm{N}$, which is much higher than the value obtained for the single-phase PVDF, which has an average $d_{33}$ of $22 \mathrm{pC} / \mathrm{N}$.

The PVDF-PZT sensor is tested for static and dynamic strain sensing properties. The voltage response of the film bonded on a beam is measured by subjecting the beam to free vibration and transient impact loading. The sensor bonded on a cantilever beam at its root is connected to the oscilloscope (see Fig. 17). First, the sensitivity of the bonded PVDF-PZT sensor to the dynamic strains induced from the free vibration of the beam is studied.

The cantilever beam specimen used is aluminum having length $L=0.33 \mathrm{~m}$, width $=0.03 \mathrm{~m}$ and thickness $h=0.0015 \mathrm{~m}$. A free vibration is induced in the beam by giving initial displacement and leaving it to vibrate on its own. The response of the PVDF-PZT sensor is recorded using oscilloscope with a sampling rate of $1 \mathrm{kHz}$. The voltage response for free vibration is shown in Fig. 18a. The frequency response is obtained by taking fast Fourier transform (FFT) of the voltage response as shown in Fig. 18b. Number of sampling points used in FFT is

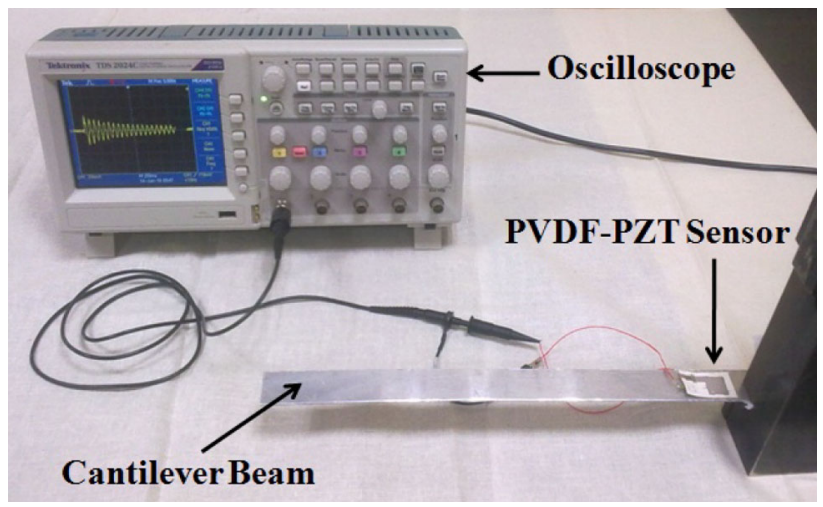

Fig. 17 Experimental setup showing the cantilever beam with PVDF-PZT nanocomposite sensor bonded on it 
$2 \times 10^{12}$. The peaks reveal the resonance frequencies of the vibrating modes of cantilever beam. The first and second natural frequencies $\left(F_{1}\right.$ and $\left.F_{2}\right)$ of the beam can be obtained using elementary beam theory (Euler-Bernoulli). The first two natural frequencies are given by

$F_{1}=\frac{1.875^{2}}{2 \pi} \sqrt{\frac{\mathrm{EI}}{\rho \mathrm{AL}^{4}}}$

$F_{1}=\frac{4.694^{2}}{2 \pi} \sqrt{\frac{\mathrm{EI}}{\rho \mathrm{AL}^{4}}}$

where $E$ is Young's modulus, $I=\mathrm{wh}^{3} / 12$ is the area moment of inertia, $\rho$ is the density and $A$ is the crosssectional area. For aluminum material with $E=60 \times 10^{9}$ and $\rho=2700$, the first two natural frequencies estimated from elementary beam theory are $F_{1}=10.48$ and $F_{2}=65.73 \mathrm{~Hz}$. The natural frequencies from the graph (Fig. 18b) are $F_{1}=9.7$ and $F_{2}=62.2 \mathrm{~Hz}$. The peaks are in good agreement with respect to the natural frequencies obtained from the elementary beam model. Thus, the developed PVDF-PZT nanocomposite film sensors have

(a)

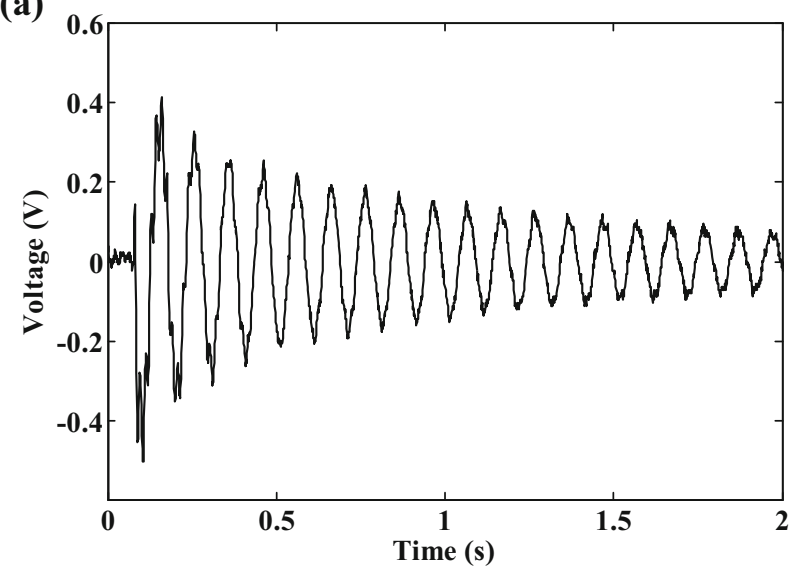

(b)

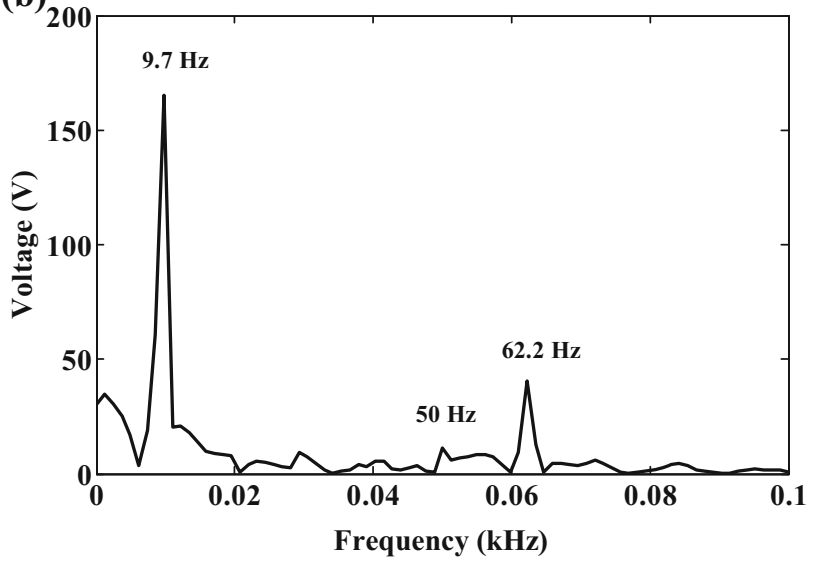

Fig. 18 Response of PVDF-PZT bonded on a cantilever beam subjected to free vibration: a voltage response, $\mathbf{b}$ frequency response the ability to capture multiple modes of vibrations accurately.

Response of the PVDF-PZT sensor to impact loading is obtained by dropping a steel ball on the tip of the cantilever beam from a known height. A ball diameter of $d=0.0095 \mathrm{~m}$ is dropped from a height of $h_{\mathrm{I}}=0.4 \mathrm{~m}$ at the tip of the cantilever beam. The steel ball hits the beam tip and falls off with negligible rebound of 1-2 mm converting entire impact energy into mechanical vibration. Magnitude of impact in terms of energy can be estimated as $E_{\mathrm{I}}=\mathrm{mgh}=0.0137 \mathrm{~N}-\mathrm{m}$. The mass of ball is found to be $m=3.5 \mathrm{~g}$. Impact response of the sensor mounted at the root of the cantilever is shown in Fig. 19a. The frequency response (FFT of the sensor signals) is shown in Fig. 19b. The sensor effectively captures the peaks in the frequency response representing several resonant frequencies of the beam. The natural frequencies from the graph (Fig. 19b) are $F_{1}=9.7 \mathrm{~Hz}$ and $F_{2}=62.9 \mathrm{~Hz}$, which again closely matche the theoretical values. Thus, the developed PVDFPZT nanocomposite films have the ability to sense dynamic strains resulting from impact. With good sensitivity, low cost and corrosion resistance, these films are suitable for

(a)

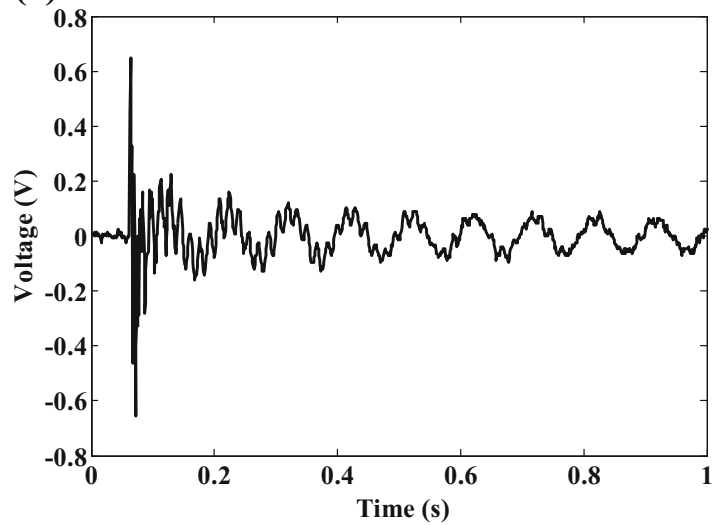

(b)

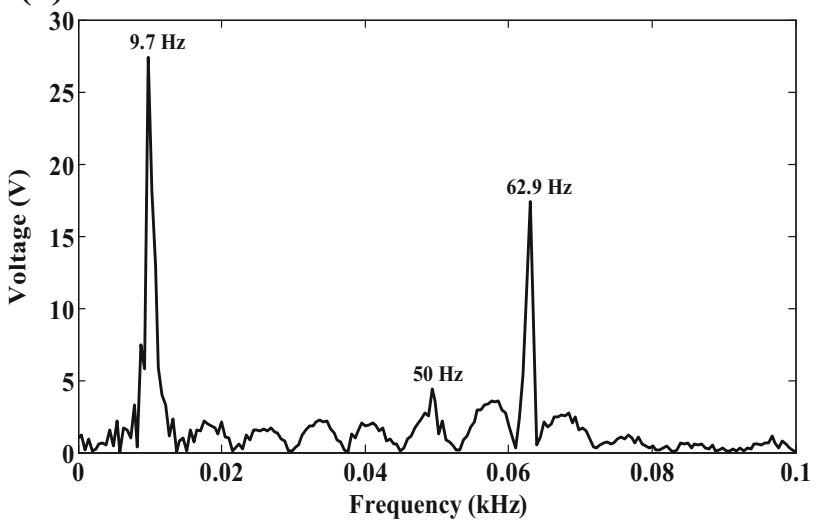

Fig. 19 Response of PVDF-PZT nanocomposite sensor bonded on a cantilever beam subjected to impact of magnitude $E=0.0137 \mathrm{~N}-\mathrm{m}$ at the cantilever tip. a Voltage response. b Frequency response 
acoustic emission monitoring and condition monitoring of aircraft structures.

Epoxy/PZT coatings The high PZT content in an epoxy matrix often leads to poor material homogeneity, which in turn lowers the mechanical properties. Recently, a potentially attractive class of epoxy called liquid crystalline thermosetting resins has been developed for the addition of PZT (van den Ende et al. 2007). The piezoelectric charge constants $\left(d_{33}\right)$ as a function of the PZT loading fraction are depicted in Fig. 20a. The piezoelectric constant increased with the increase in PZT loading. The novel epoxy/PZT nanocomposites produced possess a high piezoelectric charge constant $d_{33}$. Recently, Rathod et al. (2014) have used embedded epoxy/PZT sensors with $80 \mathrm{wt} \%$ PZT for acoustic emission sensing applications for composite laminates. The acoustic emission sensed due to fiber breakage during the tensile testing is shown in Fig. 20b. Thus, the epoxy/PZT sensors qualify as the material for impact, vibration and acoustic emission sensing in aircraft
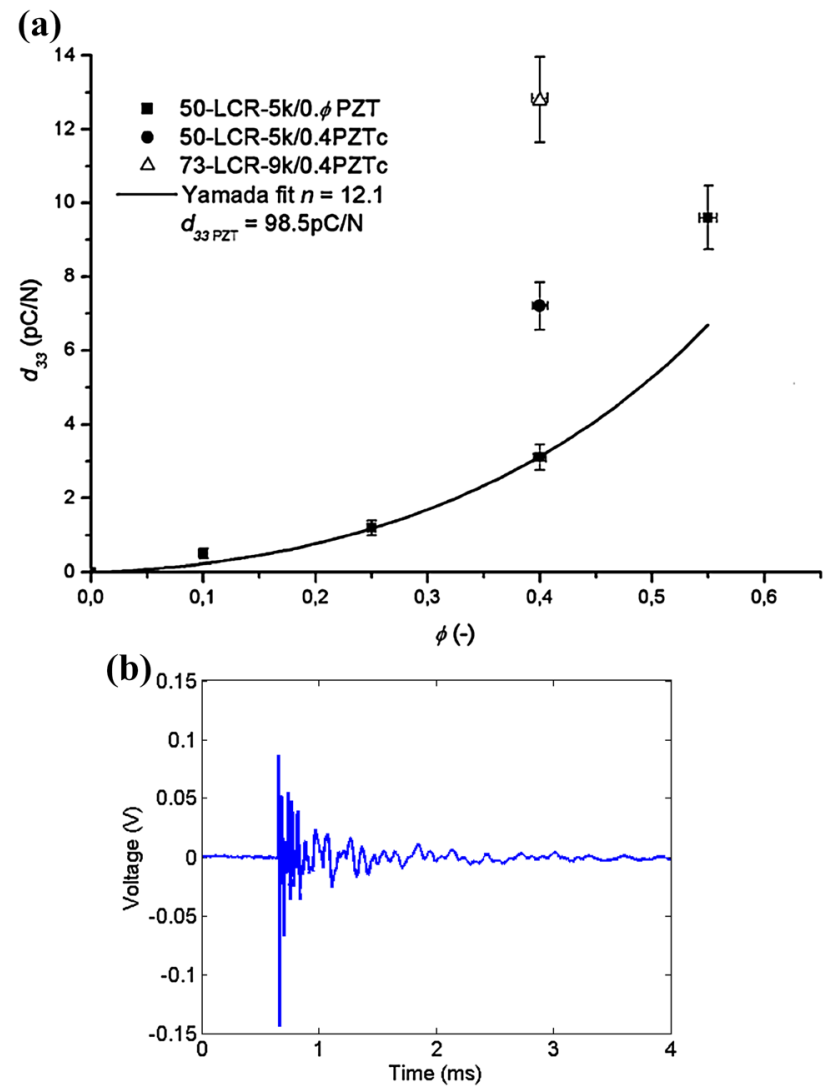

Fig. 20 a Piezoelectric coefficient $d_{33}$ of the nanocomposite material as a function of the PZT volume fraction $\phi$ (reproduced from van den Ende et al. 2007). Yamada's model is fitted to the data. b First acoustic emission observed from embedded sensors under uniaxial stretching at $1 \mathrm{~mm} / \mathrm{min}$ from embedded piezoceramic coating film (reproduced from Rathod et al. 2014) structures. These nanocomposites show the potential to replace existing piezoelectric materials for automobile and aircraft applications especially operating in harsh environments.

Polymer/ZnO films Apart from PZT nanoparticles, $\mathrm{ZnO}$ particles also exhibit inherent piezoelectricity (Wang and Song 2006; Zhu et al. 2008). (Loh and Chang 2011) developed $\mathrm{ZnO}$-embedded piezopolymer thin films for dynamic strain sensing. Piezopolymer films were prepared by dispersing $1 \mathrm{wt} \% \mathrm{ZnO}$ nanoparticles $(20 \mathrm{~nm})$ in PSS solution via $180 \mathrm{~min}$ of bath sonication $(135 \mathrm{~W}, 42 \mathrm{kHz})$ followed by $30 \mathrm{~min}$ of high-energy probe sonication (4.76 mm tip, $150 \mathrm{~W}, 22 \mathrm{kHz}$ ). The resulting mixture was mixed in an equal amount of PVA solution followed by evaporation of solvent at $25^{\circ} \mathrm{C}$ for $72 \mathrm{~h}$. The resulting PSS-PVA/ZnO nanocomposite was peeled off from the substrate whose $\mathrm{ZnO}$ weight fraction $\mathrm{W}_{\mathrm{F}}$ can be calculated from the relation

$W_{\mathrm{F}}=\frac{W_{\mathrm{ZnO}}}{W_{\mathrm{ZnO}}+W_{\mathrm{PSS}}+W_{\mathrm{PVA}}} \times 100 \%$,

where $W_{\mathrm{ZnO}}, W_{\text {PSS }}$ and $W_{\text {PVA }}$ are the mass of $\mathrm{ZnO}$, PSS and PVA, respectively. The SEM image of a nanocomposite with $W_{\mathrm{F}}=50$ is shown in Fig. 21a. The random dispersion of $\mathrm{ZnO}$ nanoparticles indicated adequate dispersion in the polymeric matrix. The sizes of agglomerates varied from 20 to $38 \mathrm{~nm}$, which are lesser than twice the size of nanoparticles. Thus, agglomeration was found to be negligible.

The nanocomposite film was poled with electrodes mounted on opposite edges of the film under moderate electric field. The poled film was mounted on a cantilever beam near the fixed end. The cantilever was subjected to free vibration, and the voltage response of nanocomposite film was measured. The output voltage $V_{\mathrm{O}}$ was normalized to take into account for the films of different sizes as

$V_{\mathrm{F}}=\frac{V_{\mathrm{O}} L_{\mathrm{F}}}{\mathrm{Wh}}$

where $L_{\mathrm{F}}$ is the distance between the electrodes, $W$ is the width of the film and $h_{\mathrm{f}}$ is the thickness of the film. The normalized voltage response of the film is shown in Fig. 21b. The response is matched with the strain measured using standard strain gauge. These films are easy to prepare, and poling requires moderate electric filed. $\mathrm{ZnO}$ enhances the piezoelectricity in piezoelectric polymers (Dodds et al. 2011). Realizing this, Meyers et al. (Meyers et al. 2013) have further demonstrated the use of $\mathrm{ZnO}$ based nanocomposites as transducer for Lamb wave-based SHM in pipe structure. Thus, $\mathrm{ZnO}$-based nanocomposites hold promising future in development of cost-effective SHM systems for aircraft structures. 
(a)

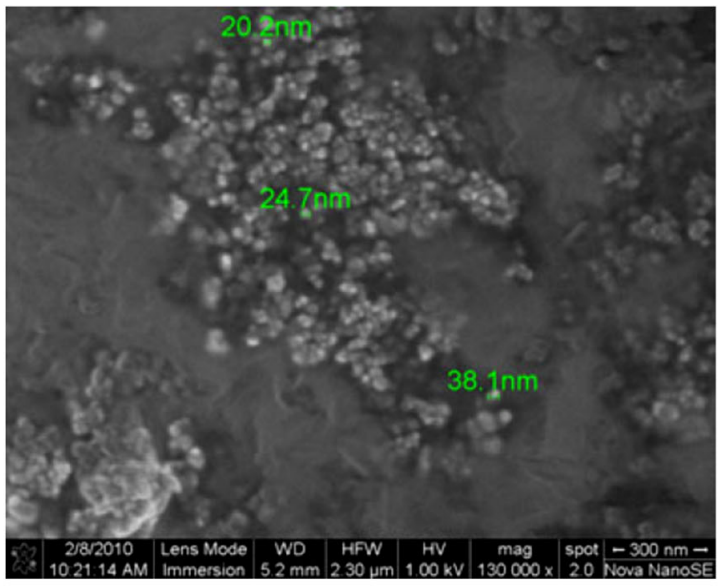

(b)

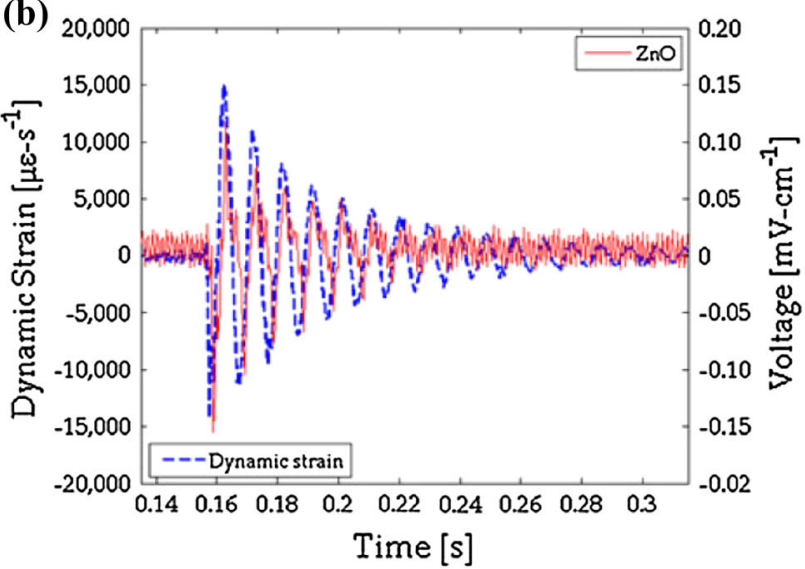

Fig. 21 a High-magnification SEM images of a PSS-PVA/ZnO thin film with 50\% weight fraction of $\mathrm{ZnO}$ showing random deposition of individual and small agglomerations of $\mathrm{ZnO}$ nanoparticles (20 and $38 \mathrm{~nm}$ ) within the polymeric matrix. b Free vibration response of a PSS-PVA/ZnO thin film with $50 \%$ weight fraction of $\mathrm{ZnO}$ overlaid with the induced dynamic strain as measured by the metal-foil strain gage (Reproduced from (Loh and Chang 2011))

\section{Piezoresistive polymer matrix nanocomposites}

Piezoresistive sensors work on the principle of change in resistance caused by the application of external stimuli. Conventional strain gauges have a gauge factor of $\sim 2$, which is very low to detect the above-mentioned dynamic strain in aircrafts. These sensors and piezoelectric transducers prove costly to monitor large aircraft structures. The cost-effective piezoresistive nanocomposite sensors serve as an alternative to such conventional sensors (Rathod et al. 2014; Sundararaman et al. 2015). Piezoresistive nanocomposites contain conductive nanofillers like CNT and $\mathrm{CB}$ that imparts conductivity.

PMMA/CNT Extremely small size of CNTs has enabled Kang et al. (Kang et al. 2006) to develop artificial neuron made up of long CNT fiber-based PMNC. SWNTs were mixed in a solvent containing PMMA as a polymer-binding agent. Mixing was done using shear force at $70{ }^{\circ} \mathrm{C}$ for $4 \mathrm{~h}$. Ultrasonic mixing was avoided since CNTs suffer damage by tip sonification and cavitation. The mix was cast in a Teflon mold and kept at room temperature to remove air, followed by curing in an oven at low vacuum (16 inch $\mathrm{Hg}$ ), at $120{ }^{\circ} \mathrm{C}$ for $12 \mathrm{~h}$. After evaporation of the solvent, a nanocomposite film of $85 \mu \mathrm{m}$ was peeled from the mold. Sensitivity of the sensor was determined by bonding it near the cantilever root. For the controlled displacement $y$ applied at cantilever tip, the strain $\varepsilon$ is estimated by beam bending relation which is given by

$\varepsilon=\frac{3 h(L-a)}{2 L^{3}} y(L)$,

where $h$ is the beam thickness, $L$ is the beam length and $a$ is the distance from beam tip to center of the sensor. Gauge factor $G_{\mathrm{f}}$ that estimates the sensitivity of piezoresistive sensor is given by

$G_{\mathrm{f}}=\frac{\Delta R}{\varepsilon}$,

where $\Delta R$ is the normalized change of resistance $\Delta R=\left(R_{\mathrm{S}}-R_{\mathrm{I}}\right) / R_{\mathrm{I}}$ with $R_{\mathrm{S}}$ being the final resistance after straining and $R_{\mathrm{I}}$ being the initial resistance. With a percolation threshold of $0.1 \%$, the variation of gauge factor is shown in Fig. 22a, where the gauge factor decreases as the CNT loading increases. The optimized content of SWNT was found to be $3 \mathrm{wt} \%$. The MWCNT-based nanocomposite neuron possesses SHM capability which can be seen from the response observed (see Fig. 22b) when it is cut half way along its width. Thus, nanocomposite neurons can monitor very large areas of an aircraft for damages. Its easy fabrication, simple instrumentation and low cost make it an excellent choice as a sensor for SHM systems for large aircrafts.

Epoxy/carbon black and Epoxy/CNT Embedded conventional sensors or transducers on the structure can act as a defect and create interference in the normal operation of the structure. For example, transducers (like PZT wafers) mounted on the surface of the skin of a wing may disturb the aerodynamic flow and reduce the efficiency of the wing. To address this problem, smart paints have been developed which are capable of sensing the dynamic strain apart from providing the protective and decorative functions of the paint. Smart composite paints developed by piezoelectric powder and epoxy resin require electroding and poling, which is complex and expensive (Egusa and Iwasawa 1998). Realizing the ability to measure the static and quasi-static pressure (Knite et al. 2004; Lu et al. 2006), Aldraihem et al. (Aldraihem et al. 2009) demonstrated the ability to measure dynamic pressure using epoxy/carbonblack nanocomposite sensor. 

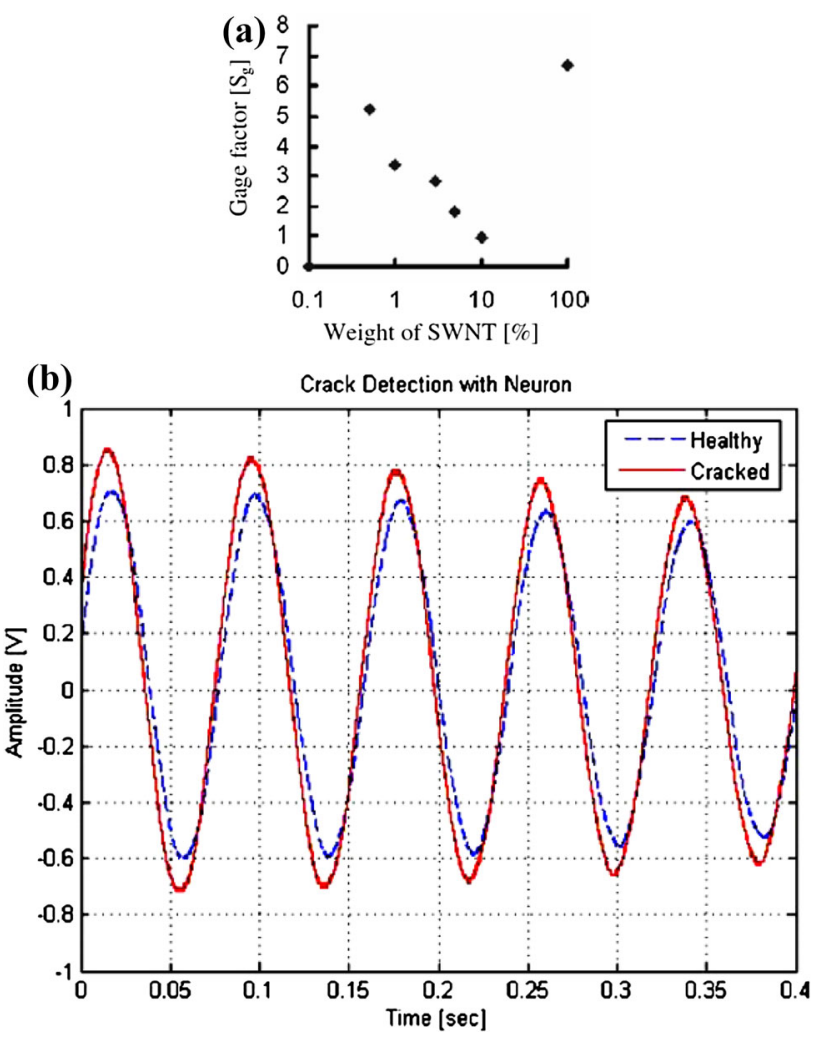

Fig. 22 a Gauge factor of PMMA/SWNT nanocomposite strain sensor, $\mathbf{b}$ dynamic response of a MWNT neuron on a beam before and after crack, demonstrating the dynamic strain sensing capability (reproduced from (Kang et al. 2006), with the permission from IOP Publishing Ltd)

The nanocomposite paint sensors were prepared by mixing CB particles $(42 \mathrm{~nm})$ in $\mathrm{PU}$ and pouring the mixture in metal mold for one day to form $0.942 \mathrm{~mm}$ thick films. Disk-shaped samples (24.6 mm diameter) were cut and electroded with silver paint as shown in Fig. 23a. The prepared paint sensors were tested by an arrangement as shown schematically in Fig. 23b. The force $F(t)$ was applied on the sensor using a shaker. The voltage response was obtained from a Whetstone's bridge. A single degree of freedom system model yields a set of coupled governing differential equations obtained by using the Hamilton's principle for electromechanical systems as

$M \ddot{x}+b \dot{x}+K x-\frac{Q_{2 \mathrm{dc}}}{(\varepsilon A)} Q_{2}=F$,

$\left(R_{0}+R_{\mathrm{a}}\right) \dot{Q}_{1}-R_{\mathrm{g}}\left(\dot{Q}_{2}-\dot{Q}_{1}\right)=0$,

$R_{\mathrm{g}}\left(\dot{Q}_{2}-\dot{Q}_{1}\right)+\frac{x_{\mathrm{dc}}}{\varepsilon A} Q_{2}-\frac{Q_{2 \mathrm{dc}}}{\varepsilon A} x=0$,

where, $M, K$ and $b$ are the equivalent mass, stiffness and damping, respectively. $x$ is the displacement of the equivalent mass. $R_{\mathrm{a}}, R_{\mathrm{g}}, R_{0}$ and $C_{\mathrm{g}}$ are the series resistance, parallel resistance, output resistance and parallel capacitance, respectively (Wang et al. 2005b). $Q_{1}$ (a)
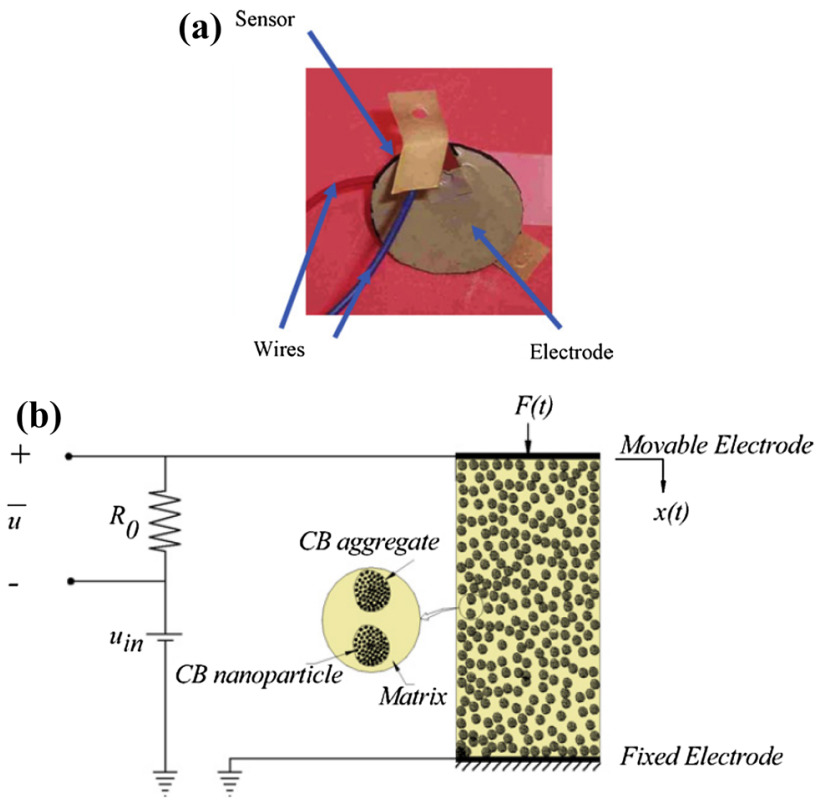

Fig. 23 a Circular sample of PU/CB nanocomposite paint sensor. b Schematic arrangement of the paint sensor and its equivalent circuit (Reproduced from (Aldraihem et al. 2009), with the permission from Elsevier)

and $Q_{2}$ are the electrical charges created by excitation, and $Q_{2 \mathrm{dc}} / \mathrm{E} A$ is the electromechanical coupling factor. $\mathrm{E}$ is the permittivity, and $A_{\mathrm{E}}$ is the electrode area. For a given $F(t)$, Eq. (12) can be solved for $x(t), Q_{1}(t)$ and $Q_{2}(t)$. Voltage change $\overline{\mathrm{u}}$ due to mechanical vibration is given by

$\bar{u}=u_{\mathrm{dc}}+u(t)=R_{0} \dot{Q}_{1 \mathrm{dc}}+R_{0} \dot{Q}_{1}$,

where the first part is due to static pressure and the second part is due to mechanical vibration. After modeling of the nanocomposite paints, Aldraihem et al. (2009) superposed its results that matched well with the experiments as shown in Fig. 24. With the availability of mathematical model and nanocomposite paint sensor, the sensor sensitivity can be studied for tuning capabilities to suit for parameters like frequency, strain level and environment conditions encountered by aerospace structures. The epoxy/CB nanocomposite paint can act as a continuously distributed sensor over large aircraft structures, fairing of launch vehicles and flexible space structures for vibration, noise and health monitoring applications. Apart from these carbon black-based pressure sensors, strain sensors have also been reported. The addition of combination of carbon black and multiwalled carbon nanotubes (MWCNT) in epoxy matrix results in a strain sensor with additional capabilities. Recently, Anand and Roy Mahapatra (2009a, b) have developed such highly sensitive strain sensor with the addition of $33 \%$ carbon black and $\sim 0.57 \%$ MWNTs that possess quasi-static and dynamic strain sensing capability, which is common parameter of interest to be monitored in 


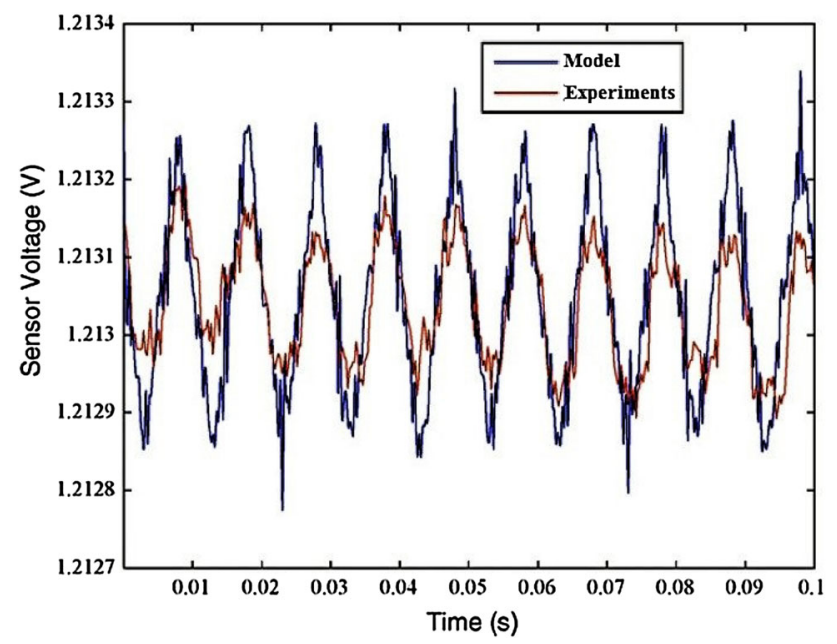

Fig. 24 Voltage response predicting the voltage drop caused by reduction in pressure over the PU/CB nanocomposite paint sensor (reproduced from (Aldraihem et al. 2009), with the permission from Elsevier)

aerospace structures. The addition of carbon black brings down the cost of the sensor. They studied the variation of MWNT concentration on the performance of the strain sensor and brought out a technique to actively tune the gauge factor by varying the bias voltage of the sensing circuit (a voltage divider).

\section{Shape memory deployable structures}

Shape memory polymers recover strain of over $50-400 \%$ upon the application of heat. This ability has attracted the application of shape memory polymers in deployable aerospace structures. Recoverable strain in shape memory polymers is several orders higher than shape memory alloys. However, recovery stress is limited due to their lower stiffness. Recoverable stress improves by the addition of reinforcements (Gall et al. 2002). Gall et al. (2004) demonstrated the storage and release of internal stress in active PMNC with $\mathrm{SiC}$ nanoreinforcements. About $20 \mathrm{wt} \%$ $\mathrm{SiC}$ nanoparticles $(700 \mathrm{~nm}$ diameter) were added to an epoxy polymer resin. A well-dispersed nanoparticle in polymer matrix was confirmed by SEM as shown in Fig. 25a (Gall et al. 2002). The stress-strain response of the epoxy/SiC nanocomposite at deformation temperature $T_{\mathrm{d}}=25{ }^{\circ} \mathrm{C}$ is shown in Fig. 25b. Elastic response exhibiting up to $50 \%$ strain followed the yielding and inelastic flow. The unloading resulted in an elastic recovery initially, followed by a nonlinear and spontaneous strain recovery. A residual inelastic strain of $35 \%$ was fully recovered by heating at $T_{\mathrm{R}}=120{ }^{\circ} \mathrm{C}$.

To determine the residual stress, a duplicate sample was held in the deformed state (2) under a fixed strain subjected to a similar heating profile observed during a (a)
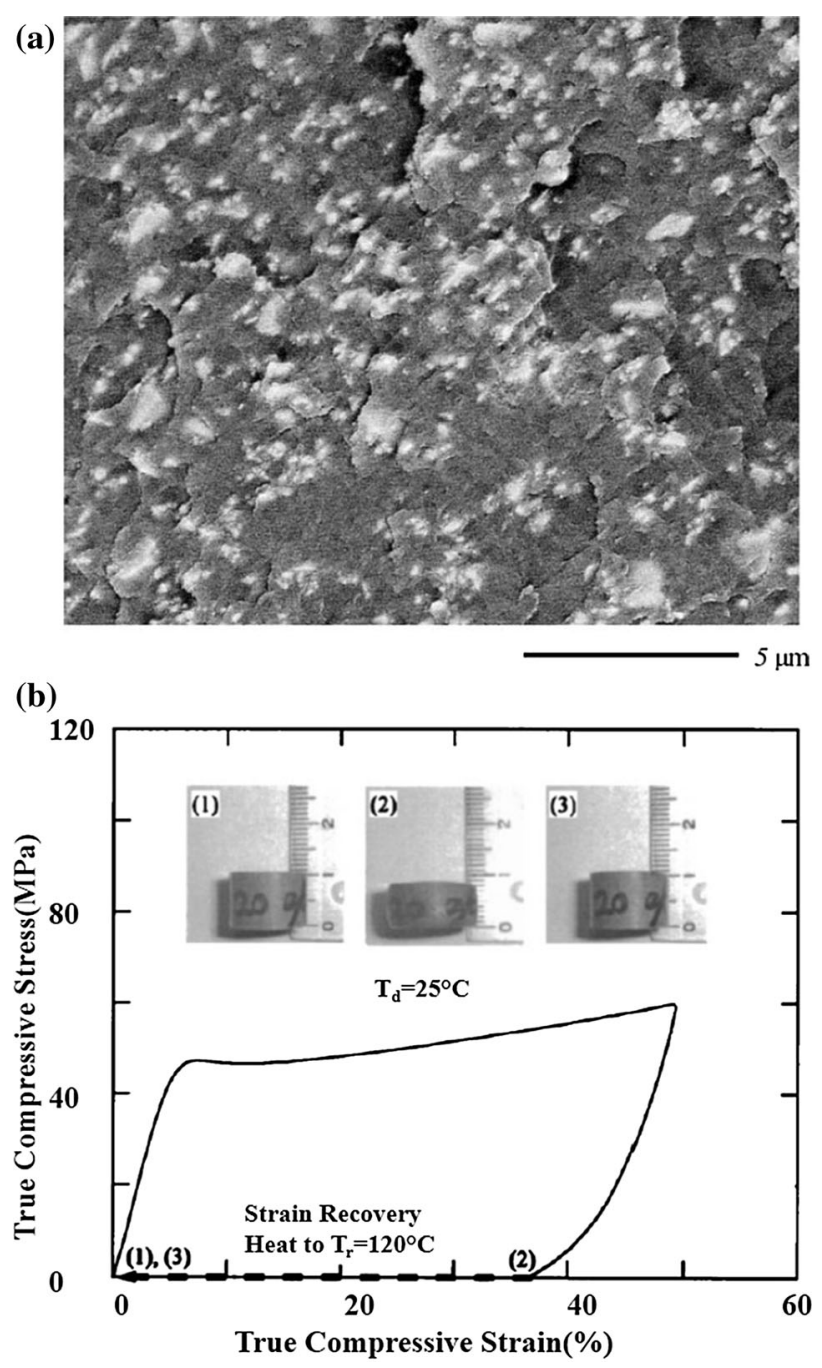

Fig. 25 a Micrographs showing SEM of epoxy/SiC nanocomposite with $40 \mathrm{wt} \% \mathrm{SiC}$ (reproduced from (Gall et al. 2002) with the permission from Elsevier). b Stress-strain curve under compression and recovery of the nanocomposite shape memory polymer. The insets display the sample shape (1) processed, (2) after compression and (3) after recovery. The sample is free from external conditions during strain recovery (reproduced from (Gall et al. 2004), with the permission from American Institute of Physics)

full strain recovery. A recovery stress of $31 \mathrm{MPa}$ was observed which is much higher than pure shape memory polymer resin. Other nanocomposites with nanofillers like CNT, carbon nanofiber, clay, CB and other organic particles also possess similar capabilities of improving the mechanical strength and shape recovery stress (Meng and $\mathrm{Hu}$ 2009). Clay imparts similar properties as $\mathrm{SiC}$ nanoparticles. CNT and CB nanofillers impart electrical and thermal conductive capabilities required by aerospace applications. The shape recovery property along with the thermal and conductive properties proposes the epoxy/SiC nanocomposites for aerospace deployable structure applications. 


\section{Conductive electromagnetic shielding structures}

Modern airliners like Boeing 787 and Airbus 380 face challenges to satisfy mechanical and electromagnetic requirements simultaneously. Electromagnetic (EM) shielding is the ability to reflect and absorb the electromagnetic radiation to act as a shield against the penetration of radiation through it (Chung 2001). Apart from providing EM protection from lightning strike, conductive composites offer intentional interference with radar-absorbing materials, equipment-level shielding, protection from highintensity radiated fields and mitigation of human exposure. Carbon fiber composites have been extensively studied for such applications since their properties can be tailored (Neo and Varadan 2004). Epoxy-based nanocomposites have been well proven for their EMI shielding capabilities.

Compared to nanocomposites with silver, iron oxide $\left(\mathrm{Fe}_{3} \mathrm{O}_{4}\right)$ and iron (Fe) nanoparticles, epoxy/CNT nanocomposites have been reported to have better EMI shielding properties (Gairola et al. 2010; Liu et al. 2014). Epoxy/CNT nanocomposites showed $99.9 \%$ energy absorption capability in the X-band (8-12.4 GHz). A SEM of epoxy/CNT nanocomposite (see Fig. 26) showed the electrical and thermal paths in the form of CNT networks (Micheli et al. 2011a). Incorporation of CNT effects the mechanical properties as shown in Table 1, in Sect. 2.1.2. The shielding effectiveness $S E$ is defined by the ratio of signal received with the sample and without sample given by

$\mathrm{SE}(\mathrm{dB})=10 \log \left[\frac{S_{\text {OPEN }}^{2}}{S_{\text {MATER }}^{2}}\right]$,

where $S_{\text {OPEN }}$ is the scattering parameter (that is, the ratio of signal transmitted to signal received by the antenna) in the presence of shielding material and $S_{\text {MATER }}$ is the scattering parameter in the absence of shielding material.

The improvement in the shielding effectiveness measured by a vector network analyzer is shown in Fig. 27 (Micheli et al. 2011a). The measurements were done with the sample normal to the direction of electromagnetic wave propagation. The measured $S E$ matched well with the $S E$ predicted by a mathematical model following a winning particle optimization algorithm (Micheli et al. 2011b). The high shielding effectiveness property of $10 \mathrm{wt} \% \mathrm{CNT}$ nanocomposite was comparable to that of an aluminum enclosure. Addition of multiple layers of shielding materials can give rise to additional reflections, which increases the $S E$. Epoxy/CNT nanocomposites also showed flame retardancy due to the formation of a jammed network structure in polymeric matrix (Im et al. 2010). Moreover,

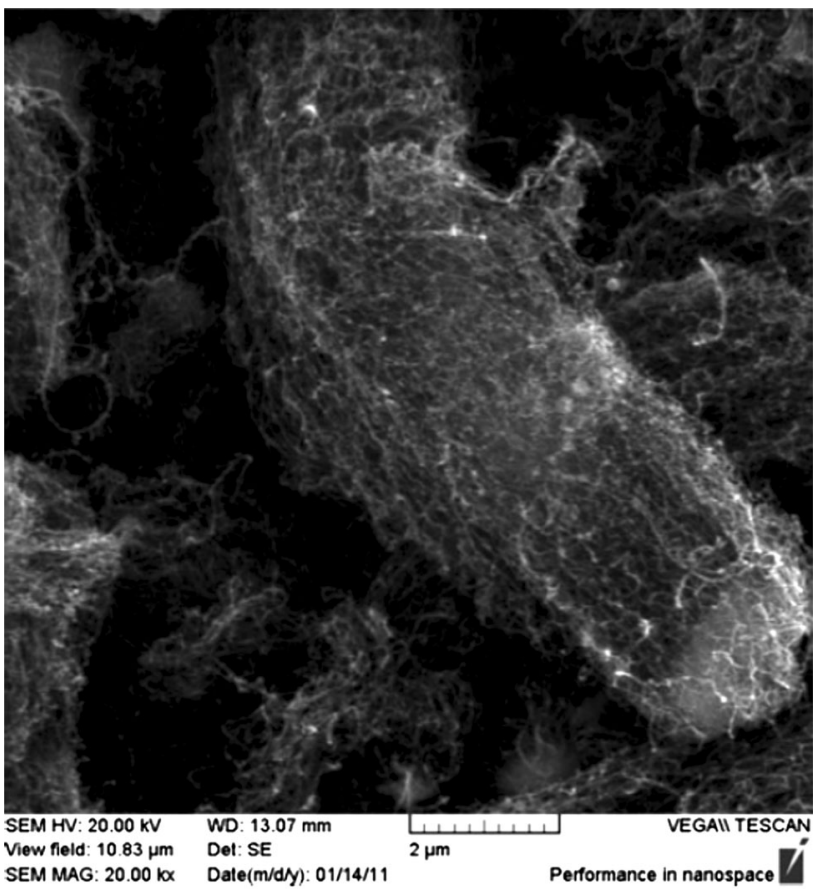

Fig. 26 SEM image of epoxy/CNT nanocomposite with 3 wt $\%$ MWCNTs (reproduced from (Micheli et al. 2011a), with the permission from Elsevier)

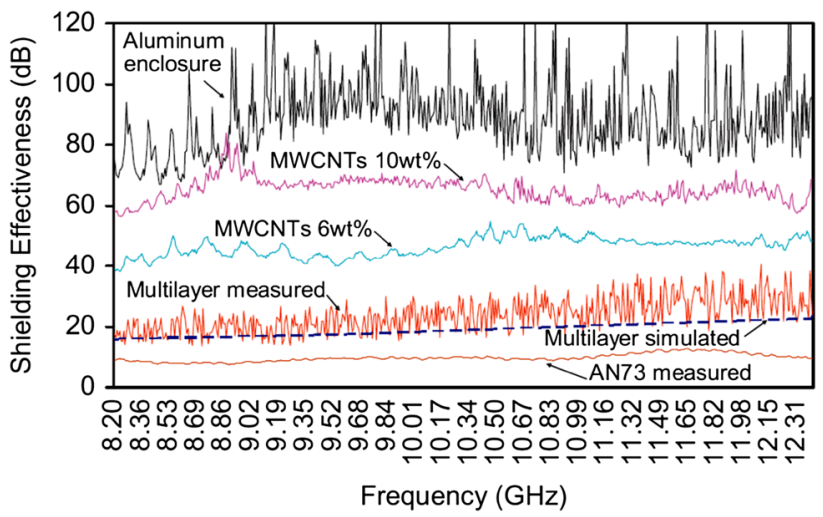

Fig. 27 Shielding effectiveness of a shielding structure with single layer of $6 \mathrm{wt} \%$ MWCNTs and $10 \mathrm{wt} \%$ MWCNTs (reproduced from (Micheli et al. 2011a), with the permission from Elsevier)

multifunctional properties like high thermal and electrical conductivities and mechanical properties make them suitable for aerospace application where strength, lightning strike protection and EMI shielding are required (Im et al. 2010). EM and radar-absorbing capabilities can be realized using biphase and triphase carbon fiber-reinforced nanocomposites (De Rosa et al. 2008). Thus, these nanocomposites can be installed on aircrafts as advanced EM shields for stealth applications or EMI suppression. 


\section{Ceramic matrix nanocomposites}

Ceramics are brittle materials susceptible to fracture. Most aerospace components are subjected to vibration and fatigue for which ceramics are not suitable. However, ceramics are hard, inert and stable at higher temperature levels. Aircraft components subjected to elevated temperature levels and corrosive environment require such properties. Significant effort has been put to impart toughness to the ceramic materials. To prevent ceramics from fracture, ductile phase is added which improves strength and fracture toughness. Properties of the nanocomposite relate primarily to the ratio of surface area/volume and relation of different phases of matrix and reinforcements. Various CMNCs for aerospace applications with their properties and the related morphology at nanoscale are presented next.

\section{Alumina/MWNT for EM shielding applications}

Alumina is typically used in structural applications but is an electrical insulator for which it cannot be used in aircrafts. CNTs are seen to impart toughness to the ceramic matrix with improved properties compared to the conventional carbon and $\mathrm{SiC}$ fibers, which just imparts toughness. MWNTs show multichannel, quasi-ballistic conducting behavior due to the participation of multiple walls in the electrical transport ( $\mathrm{Li}$ et al. 2005). Their large diameter results in small band gap for semiconductor activity. High current density and conductivity $\left(10^{7} \mathrm{~A} / \mathrm{cm}\right.$ and $1.85 \times 10^{3} \mathrm{~S} / \mathrm{cm}$, respectively) of MWNTs render them electrically conductive always (Ando et al. 1999). Loading of MWNTs in alumina results in improved structural integrity and electrical conductivity (Curtin and Sheldon 2004). Thus, it is worth to present the preparation method and alternating current (AC) and DC conductivity studies of alumina/MWNT nanocomposites developed by Ahmad and Pan (2009). MWNTs were mixed ultrasonically with alumina in ethanol followed by ball milling for $24 \mathrm{~h}$. The mixture was dried and transferred in cylindrical graphite mold to be plasma sintered at $1400{ }^{\circ} \mathrm{C}$ in vacuum under a pressure of $50 \mathrm{MPa}$.

Figure 28 shows a SEM of MWNT/alumina nanocomposite (fractured surface) with $3 \mathrm{wt} \%$ MWNT. A welldispersed intertwining network formed by MWNTs at the grain boundaries can be seen. Conduction via tube-tube within the bundle and interlinked network of ropes results in the overall conduction in such nanocomposite. A standard four-point probe method gave the DC conductivity as shown in Fig. 29a. Insulator conductor transition was exhibited between 0.4 and $0.5 \mathrm{wt} \%$ of MWNTs. Eight order increase in conductivity was observed at $0.5 \%$

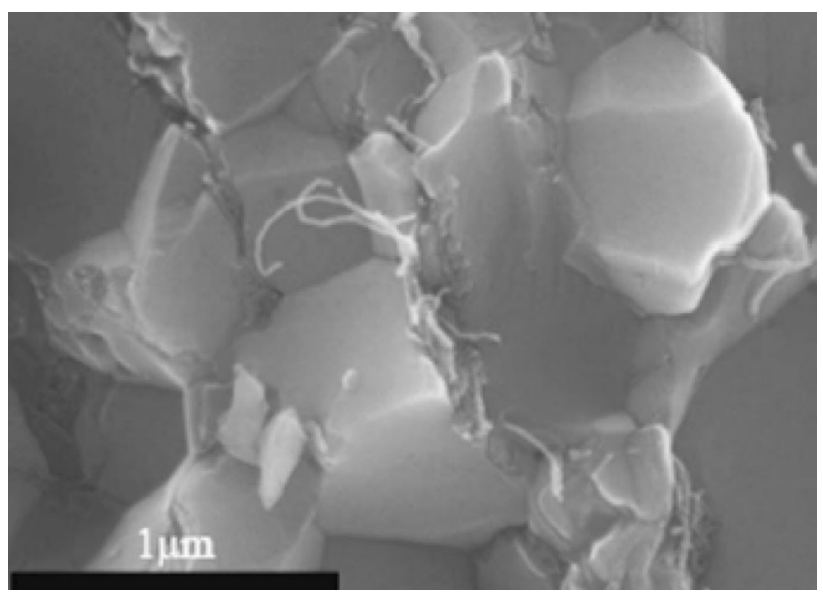

Fig. 28 SEM showing a fractured surface of MWNT/alumina nanocomposite with uniform distribution of MWNTs (reproduced from (Ahmad and Pan 2009), with the permission from Elsevier)

MWNT after which a lesser rise was observed. The power law followed by the conductivity (Stauffer and Aharony $1994)$ is given by

$\sigma_{\mathrm{dc}}=\sigma_{\mathrm{c}}\left(P_{\mathrm{MWNT}}-P_{\mathrm{c}}\right)^{t}$, for $P_{\mathrm{MWNT}}>P_{\mathrm{c}}$,

where $\sigma_{\mathrm{dc}}$ and $\sigma_{\mathrm{c}}$ are the DC conductivities of the nanocomposite and the filler, respectively. $P_{\mathrm{MWNT}}$ and $P_{\mathrm{c}}$ are the weight fraction and percolation threshold, respectively.

The fit in Fig. 29a has the $t=1.82$ (represents the dimensionality of the system) and $P_{\mathrm{c}}=0.45 \mathrm{wt} \%$. A smaller amount of $t$ is contributed by the hopping between weakly connected parts of the network (Reghu et al. 1994). For $t<2$, thermally induced hopping transport dominates the conduction. Increase in wt $\%$ of MWNTs enhances the conductive path by increasing the inter-nanotube connections. Tunneling resistance is caused by inter-nanotube connections ( $\mathrm{Li}$ et al. 2007). The conductivity of the nanocomposites is also seen to increase with temperature. The carrier mobility and thermally generated carrier mobility increase with temperature causing semiconductorlike effect. Fluctuation-induced tunneling model is used to describe this effect as a change of barrier height by fluctuation of thermal voltage causing the tunneling of the electrons (Ping 1980). The conductivity is given by (Sheng et al. 1978)

$\sigma_{\mathrm{dc}} \propto \exp \left[\frac{-T_{1}}{T+T_{0}}\right]$

where $T_{1}=w A \varepsilon_{0}^{2} / 8 \pi k_{\mathrm{B}}, T_{0}=2 T_{1} / \pi w \chi, T$ is the absolute temperature, $k_{\mathrm{B}}$ is the Boltzman's constant, $\chi=\left(2 m_{\mathrm{c}} V_{0} /\right.$ $\left.h^{2}\right)^{1 / 2}, e_{0}=4 V_{0} /$ ew, $m_{\mathrm{c}}$ is the electron mass, $e$ is the charge, $V_{0}$ is the potential barrier height, $w$ is the insulating layer width and $A_{\mathrm{J}}$ is the area of capacitance formed at the junction. 


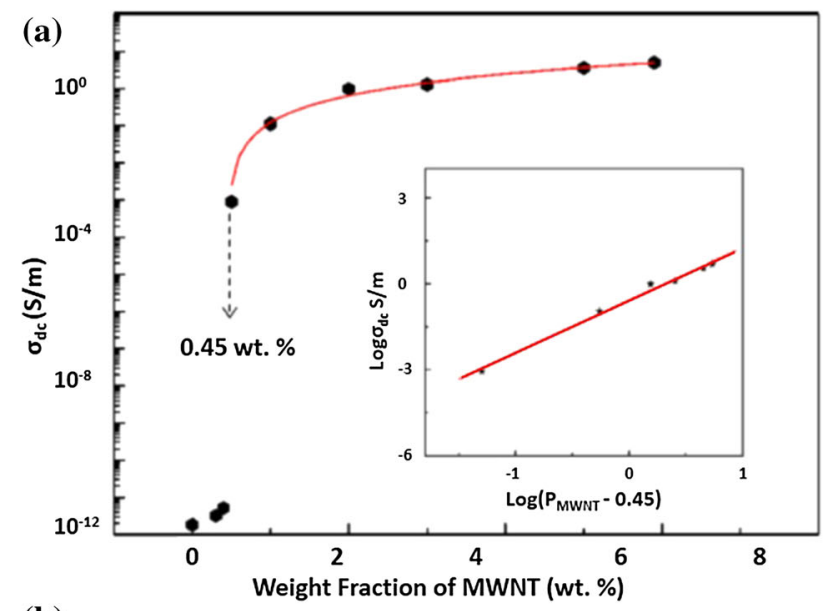

(b)

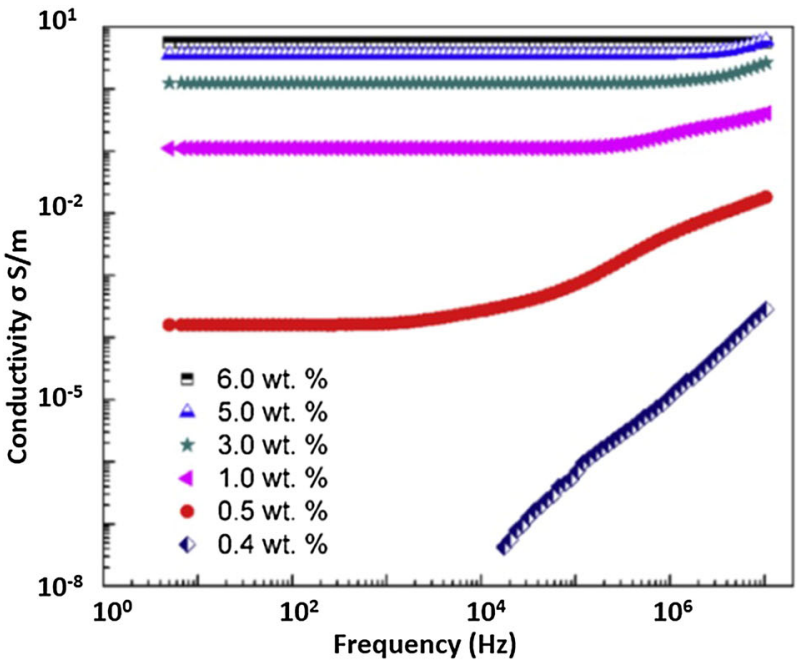

Fig. 29 a DC conductivity of the MWNT/alumina nanocomposites as a function of MWNT contents. Inset shows DC conductivity with $\left(P_{\mathrm{MWNT}}-P_{\mathrm{c}}\right)$. b Frequency-dependent conductivity of the MWNT/ alumina nanocomposites (Reproduced from (Ahmad and Pan 2009), with the permission from Elsevier)

AC conductivity studies were done using an impedance analyzer at frequency ranging from 5 to $15 \mathrm{MHz}$ at room temperature. The conductivity was initially constant and increased at higher frequencies for samples just above the percolation threshold (0.4 wt \%) (see Fig. 29b). For higher MWCNT percentage, the conductivity becomes frequency independent. Below percolation threshold, the conductivity increases linearly with the slope of curve closer to unity indicating highly resistive material. The curve obeys the expression of dielectric conductivity $\sigma=2 \Pi f_{\varepsilon} \varepsilon_{0}$, where $\varepsilon_{\mathrm{i}}$ is the imaginary part of permittivity and $\varepsilon_{0}$ is the vacuum permittivity. In addition to the electrical properties, they possess excellent resistance to chemical, corrosion, extreme radiation and ultraviolet exposure generally encountered by aerospace structures. With these properties, MWNT alumina nanocomposites are suitable as electrostatic dissipation materials for aerospace structures.

\section{Alumina/MWNT for SHM applications}

Apart from applications like energy, transportation, defense, sporting goods and civil infrastructure, CMNCs are being researched for automotive and aerospace applications (De Volder et al. 2013). Automotive and aerospace applications demand SHM capabilities for safety of life and infrastructure, as explained in Sect. 2.4. Inam et al. (2014) presented the SHM capability in ceramic/carbon nanocomposite. SWNTs were dispersed in DMF by ultrasonication for $30 \mathrm{~min}$ followed by hand mixing of alumina nanopowder (particle size $<50 \mathrm{~nm}$ ). Ball milling of the mixture was done for $7 \mathrm{~h}$ followed by drying in rotary dryer for $12 \mathrm{~h}\left(60^{\circ} \mathrm{C}\right)$ and in vacuum over for $48 \mathrm{~h}$ $\left(100{ }^{\circ} \mathrm{C}\right)$. The mixture was ground and sieved at 250 mesh followed by drying in vacuum oven for $48 \mathrm{~h}\left(100{ }^{\circ} \mathrm{C}\right)$. Nanocomposites were prepared by spark plasma sintering (Jackson et al. 2010) from which $18 \times 3 \times 3 \mathrm{~mm}$ bars were prepared for various tests.

Images in Fig. 30 show the fractured microstructure of alumina/CNT nanocomposite obtained from SEM. Homogeneously dispersed CNTs in various isolated location and a CNT mesh in central fractured location indicated uniform dispersion obtained by milling and drying process. Vickers indentations were performed with $500 \mathrm{~g}$ load and $10 \mathrm{~s}$ of indentation time. Five equally spaced indents were produced with parallel measurement of bulk electrical conductivity at room temperature using a four-point method. A drastic change in electrical conductivity was seen in alumina/CNT nanocomposite with number of indents. CNT and graphene-based nanocomposites showed higher sensitivity toward indentation damage. Also superposed are the results obtained from alumina/CB and alumina/graphene nanoplatelets. The indentation causes microcracks attributing to the fracture of fibers that result in reduced conductivity. Higher fracture toughness was also seen in these nanocomposites. Thus, with improved fracture toughness and safety provided by SHM capability, alumina/CNT nanocomposites can be used as structural components of aircraft, spacecraft and reentry vehicle operating at higher temperature.

\section{Aerospace tribology}

Aerospace systems involve costly inspection and maintenance procedures due to friction and wear in various movable devices. The parts that require periodic maintenance are the bearing surfaces of gears, pumps, reaction wheels, latches, sensor orientation mechanisms, actuators, antenna drives, solar arrays and gyroscopes (Voevodin et al. 1999). The life of bearing surfaces is affected by the loading, operating conditions and environmental conditions. Loading results in typical contact stress of $10^{7}-10^{10}$ 


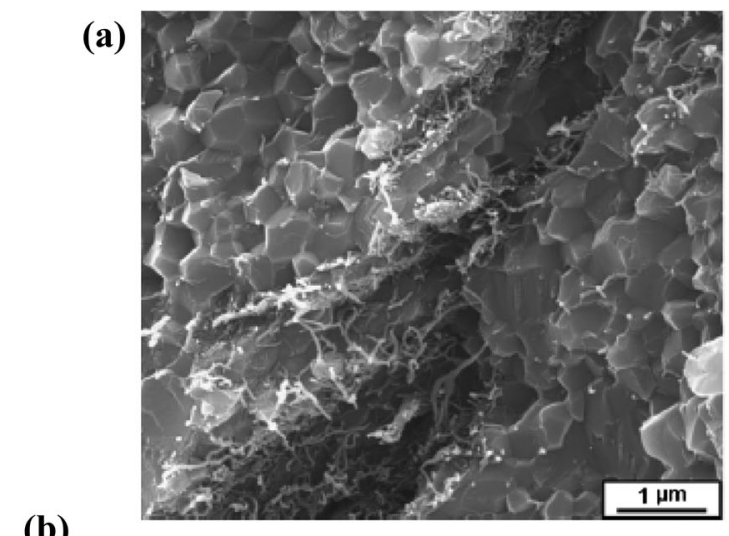

(b)

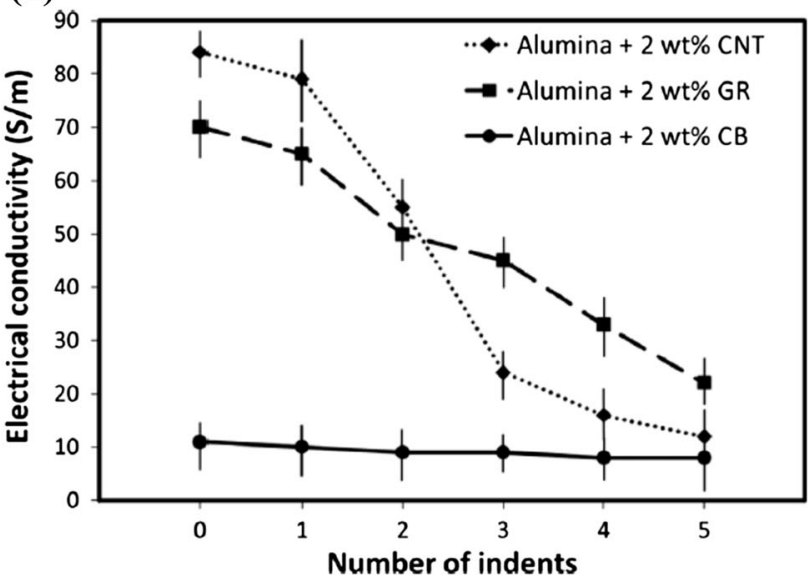

Fig. 30 a Fractured microstructure of alumina/carbon nanocomposites obtained from SEM. b Change in electrical conductivity of alumina/carbon nanocomposites due to Vickers indentation (Reproduced from (Inam et al. 2014), with the permission from Elsevier)

Pa with sliding velocity varying from 0 to $20 \mathrm{~m} / \mathrm{s}$. This type of loading is typically a result of vibrations that causes wear and fatigue of the bearing surfaces. Extreme operating conditions at high and low altitude subject the tribological surfaces to variation of humidity and temperature ( -40 to $+300{ }^{\circ} \mathrm{C}$ for aircrafts and -100 to $+100{ }^{\circ} \mathrm{C}$ for space objects). The environment cycling and dust experienced by aircrafts also add to the problems of wear in bearing surfaces. High altitude aircrafts like SR-71 reconnaissance plane 'Blackbird' and spacecraft are subjected to atomic oxygen and electrostatically attracted dust causing abrasive wear (Graham 1997). Forthcoming space applications such as bearings for moment control devices and solar array joints require $10^{9}-10^{10}$ and $10^{6}-10^{8}$ cycles, respectively, for a span of 15-30 years. Conventionally, solid lubricants like polymers, soft metals, PTFE and dichalcogenides have been used. Liquid lubricants like mineral oils and synthetic oils are used in sealed assemblies. Such lubrication and wear reduction methods cannot withstand the endurance requirements of aerospace like abrasion and oxidation resistance.
To meet the aerospace requirements, transition-metal dichalcogenides like $\mathrm{MoS}_{2}, \mathrm{WS}_{2}$, niobium diselenide $\left(\mathrm{NbSe}_{2}\right)$ are mixed with organic and inorganic binders and the resulting mixture is deposited by spray or vacuum deposition process (Bhushan and Gupta 1991). The vacuum deposition technique allows the control of morphology, structure, chemistry and thickness of the coatings. Vacuum deposition also allows hard and lubricious phases in nanocomposite coatings. With these capabilities, advanced hard coatings that meet the aerospace endurance requirements can be prepared to reduce wear and friction (Miyoshi et al. 1997). Two-phase titanium carbide/DLC (TiC/DLC) and WC/DLC nanocomposites are not suitable in high-vacuum environment (Voevodin et al. 1996a, 1996b) due to increase in friction from the graphitization of DLC. Space lubricants like $\mathrm{MoS}_{2}$ or $\mathrm{WS}_{2}$ embedded in carbide/DLC/WC dichalcogenide composite last more than million cycles in space environment with humid/dry cycling (Voevodin et al. 1998). An adaptive WC/DLC/WS ${ }_{2}$ coating developed by Voevodin et al. (1999) imparts wear resistance and mechanical strength due to the presence of hard and crystalline WC. Amorphous DLC provides low wear and friction, whereas $\mathrm{WS}_{2}$ phase provides lubrication in vacuum meeting the aerospace requirements.

Voevodin et al. (1996a, 1996b) produced WC/DLC/WS 2 coatings by magnetron assisted pulsed laser deposition or by laser ablation. Approximately $0.5-\mu \mathrm{m}$ thick coatings were obtained, which were polished to $0.02 \mu \mathrm{m} R_{\mathrm{a}}$. At a vacuum of 10-6 $\mathrm{Pa}$, the magnetron was operated with $\mathrm{WS}_{2}$ target $8 \mathrm{~W}-\mathrm{cm}^{-2}$ with $0.2 \mathrm{~Pa}$ argon such that the plasma was directed at $45^{\circ}$ to the surface. A controlled laser beam ablates the graphite surface at $45^{\circ}$ angle such that the composition was controlled by varying the $\mathrm{WS}_{2}$ sector area. The microstructure and the diffraction pattern demonstrate hexagonal $\mathrm{WS}_{2}$ crystal structure (see Fig. 31). One type of basal planes is perpendicular to the crystal axis (c-axis) with the spacing of $0.6 \mathrm{~nm}$ between the planes. Another set of basal planes have the spacing of $3 \mathrm{~nm}$ with the c-axis parallel to them. Grains of 5-10 nm randomly orient in the surrounding with dark and gray areas representing $\beta$-WC and DLC. WC/DLC/WS ${ }_{2}$ coatings consist of nearly amorphous or extremely nanocrystalline phases with $10 \mathrm{~nm}$ dimension.

A nanoindenter microprobe loaded in the range of $1 \mathrm{mN}$ was used to determine hardness and Young's moduli. Maximum penetration and load displacement curves were used to determine hardness and moduli, respectively. The hardness of the nanocomposite as a function of sulfur content is shown in Fig. 32. The coating hardness decreased from 15 to $7 \mathrm{GPa}$ at $15-20 \%$ sulfur. At this composition, the elastic modulus also decreased from 230 to $250 \mathrm{GPa}$ to $100-130 \mathrm{GPa}$. The drop in properties is the 
Fig. 31 Transmission electron microscope images of the $\mathrm{WC} /$ DLC/WS $\mathrm{W}_{2}$ coatings with $29 \%$ sulfur contents with the inset image showing selected-area diffraction patterns. The image on the right is the zoomed in image of the selected spot (Reproduced from (Voevodin et al. 1999), with the permission from Elsevier)
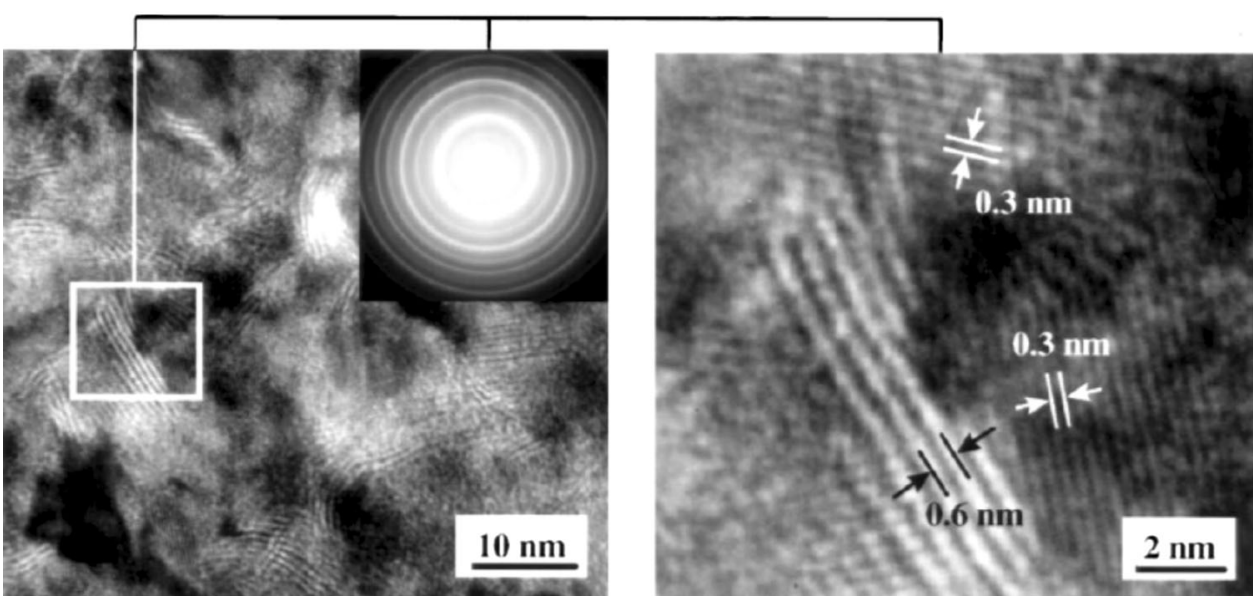

results of the segregation of soft $\mathrm{WS}_{2}$ in the material. Due to the multiphase material composition, the entire range of hardness lies in between the hardness of WC having 24-28 GPa and $\mathrm{WS}_{2}$ having $3 \mathrm{GPa}$ (Bhushan and Gupta 1991). However, this slight reduction in hardness can result in significant low wear rates and increased endurance.

A ball on disk tribometer was used to measure the friction of the nanocomposite coatings. Hundred gm of load was applied on a stainless steel ball with sliding speed of $10 \mathrm{~m} / \mathrm{min}$. The data were obtained on steady wear conditions over 50,000 sliding cycles. Similarities were seen in the variation of friction coefficient obtained in vacuum and nitrogen environments. A sharp reduction of friction coefficient resulted with $15-20 \%$ sulfur due to the formation of thick transfer films. Low friction resulted from $\mathrm{WS}_{2}$ due to week van der Waals forces between layers of S-W-S planes facilitating inter- and intra-crystalline slip (Prasad and Zabinski 1997). Reorientation and

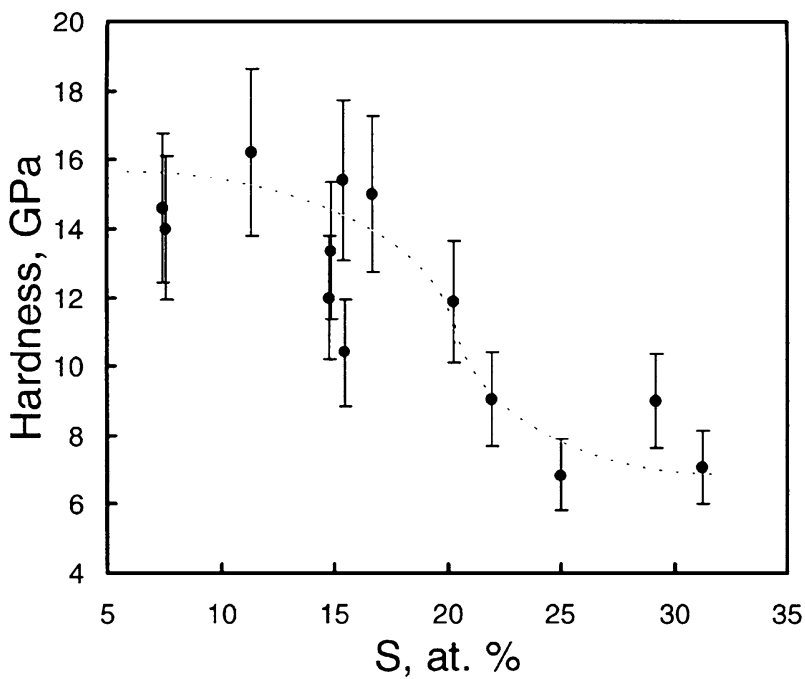

Fig. 32 Variation in the hardness of $\mathrm{WC} / \mathrm{DLC} / \mathrm{WS}_{2}$ coatings as a function of sulfur content (reproduced from (Voevodin et al. 1999), with the permission from Elsevier) conglomeration of $\mathrm{WS}_{2}$ grains were observed by Raman analysis. Friction coefficient obtained from the tests in vacuum was found to be highest when compared to friction coefficients in moist air and nitrogen. A lower friction coefficient of 0.1 was observed at a lower sulfur content. This was due to the formation of amorphous carbon in the wear tracks. With 15-20\% sulfur, $\mathrm{WS}_{3}$ and tungsten trioxide $\left(\mathrm{WO}_{3}\right)$ phases were detected by Raman analysis. Oxidation of ball material also leads to the occurrence of $\mathrm{Fe}_{2} \mathrm{O}_{3}$ and chrome oxide. This transfer of ball material leads to an increase in coefficient of friction. Coatings with more than $20 \%$ sulfur show lower coefficient of friction. The friction coefficient study indicates the need of $20 \%$ sulfur coating.

Endurance tests were carried out in space conditions (vacuum) of long duration with 2,000,000 cycles. A profilometer and an optical microscope were used to track the area and diameter of the wear track used in the estimation of normalized wear volume $\left(\mathrm{mm}^{3} / \mathrm{N}-\mathrm{m}\right)$. Figure 33 shows the variation of wear rate with sulfur content after 10,000 sliding cycles in different environments. The wear rate decreases considerably at $20 \%$ sulfur content. A similar behavior was seen in the variation of friction coefficient. Reverse dependence was seen in moist air. With 20-30\% sulfur, the wear rate was lowest in vacuum. This lowest wear rate is due to the formation of $\mathrm{WO}_{3}$. The coatings with $22 \%$ sulfur further endured two million sliding cycles with friction coefficient of 0.03-0.06. Slight reduction in friction with test duration was seen due to the ongoing process of reorientation and accumulation of $\mathrm{WS}_{2}$ phase. This type of higher initial wear followed by long period of low wear is typical in solid lubricants (Singer et al. 1996).

Additional requirement posed by aerospace bearing applications is the stability of the performance in environment with varying humidity, for which the test environment was varied between dry nitrogen $<0.05 \% \mathrm{RH}$ and moist air with $50 \% \mathrm{RH}$ for every 5000 sliding cycles. The coatings with $15 \%$ sulfur showed friction coefficient of 


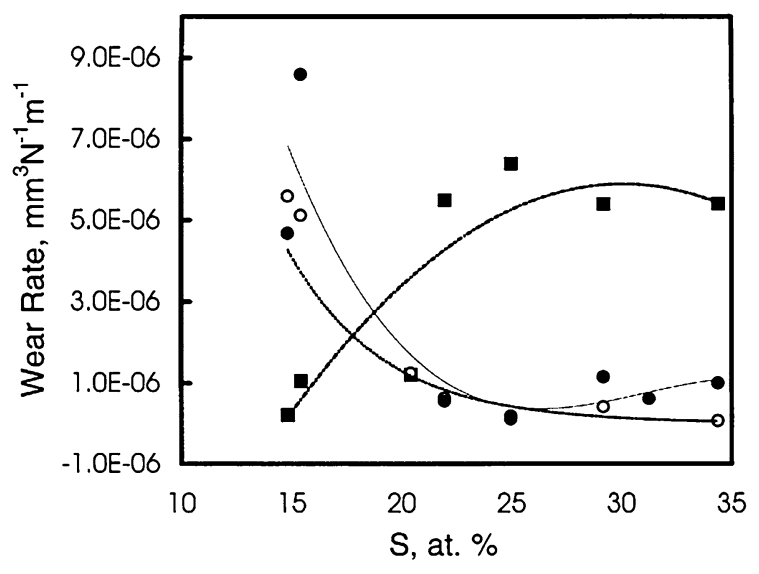

Fig. 33 Variation of wear rates as a function of sulfur content for moist air (filled square), dry nitrogen (circle) and high vacuum (filled circle) (reproduced from (Voevodin et al. 1999), with the permission from Elsevier)

$0.02-0.05$ and $0.1-0.2$ at low and high humidity, respectively. $\mathrm{WS}_{2}$ and DLC provided the lubrication in low and high humid conditions, respectively. The coatings have the capability to adapt to the humidity conditions by destroying the $\mathrm{WS}_{2}$ planes by oxidation, replacing them with graphite planes formed from DLC through friction-induced transformation. The next dry cycle causes desorption of water molecules resulting in the wear of graphite sheets leading to the exposure of $\mathrm{WS}_{2}$ grains. The low wear, low friction and adaptability to changing environment of WC/DLC/ $\mathrm{WS}_{2}$ coatings fulfill the criteria for space applications, which is wear rate $<10-6 \mathrm{~mm}^{3} / \mathrm{N}-\mathrm{m}$ and friction coefficient $<0.1$ (Voevodin et al. 1999). Thus, the adaptive WC/DLC/ $\mathrm{WS}_{2}$ coatings are excellent tribological materials for selflubricated wear-resistant coatings for aerospace and space applications that demand excellent endurance and low wear rates in different environments.

\section{Perspectives and challenges}

Upcoming potentials of nanocomposites can be easily guessed by the massive investments of researchers and industrialists worldwide in research and development. For instance, General Motors have used nanoclay and talc for structural applications. GE and Cabot in USA are using nanocomposites in the form of nanosmart switches, conductive polymers and sensors. Such commercialization will ease the availability and bring down the cost of nanocomposites. Advancement of processing methods together with the molecular level control of nanomaterials distribution and interaction with the matrix material is seen to optimize the properties and performance of nanocomposites. Thus, the nanocomposites have a good chance in the application of advanced aerospace systems. Advances in robust manufacturing technology for nanocomposites will enable their migration in applications like electronics, thin films, ultralight aerostructures and shape memory polymers for space-deployable spacecrafts. Electrochromic polymers are being developed for thermo-optical uses, whereas electroactive polymers have the potentials to be used in the design of photoactive structures suitable for space missions. Recent advancements in polymer nanocomposites and the current research trend are creating new opportunities to develop next-generation aircraft and space structures (Youssef 2013). In case of PMNC, fire retardancy and weatherability is seen to gain much importance. In case of CMNC coatings, engine components, temperature sensors and high temperature structures can receive much importance. The PMNCs are far ahead in development when compared to CMNC and MMNCs. This is due to their development being driven by funding and their technology readiness or maturity level. The new manufacturing techniques for chirally sorted CNTs (Ganzhorn et al. 2011) and long CNTs ranging to half meter (Zhang et al. 2013) have the potential to open new areas of research and development for sensing and structural applications for aerospace industry.

The present paper focusses on the available solutions that suit aerospace/space applications. However for these solutions to be incorporated practically in various different aerospace structures, aerospace certification requirements may pose additional studies to be done related to manufacturability, reliability, uniformity and repeatability. Affordability and availability are other aspects which aerospace industry will consider to curb cost and save time. Nanocomposites face several challenges in their processing and characterization. For instance, processing of nanofibers is difficult which if solved will yield ultralightweight components as compared to their microfiber counterparts. Development of nanocomposites involves interdisciplinary research involving chemistry, physics, materials science and engineering to relate various properties with the nanostructure. Improvement of mechanical properties by surface modification of nanofiber and determination of properties by modeling and simulation can aid in the development of nanocomposites. Dispersion, alignment, volume fraction and ease of fabrication along with their cost factor are the critical parameters to decide the potential of nanocomposites (Thostenson et al. 2005). A processing nanostructure property map developed by Ashby (1992) provides the method to take into account of most of these critical factors.

Release of nanoparticles in environment is hazardous since they can interact with cells by their reactivity, nanosized structure and surface area. This has received huge attention in recent times to study the human and environmental exposure to nanomaterials via waste 
materials and other pathways (Aschberger et al. 2011; Dreher 2004). A stringent requirement for clean environment demands the use of fillers of natural origin to obtain recyclable and biodegradable nanocomposites. Natural fillers are minerals, vegetal materials, reinforcements based on common elements, layered double hydroxides and layered hydroxide salts (Camargo et al. 2009). Similarly, environment-friendly polymer matrix can be derived from plasticized polyhydroxylalkanoates, saccharides, polylactide and poly ( $\varepsilon$-caprolactone). The low cost of these fillers and matrix will enable their use in variety of aerospace applications.

\section{Concluding remarks}

Nanocomposite is an evolving area of interdisciplinary research motivated by nanotechnology. The capability to tailor materials at nanoscale has opened up the possibilities of developing next-generation multifunctional materials suitable to meet the requirements posed by the aerospace industry. Structural failure, lightning strike, icing and erosion pose several requirements on aerospace systems. The aerospace requirements like mechanical, chemical, thermal and electrical properties are achieved by polymer and CMNC with the nanofillers like nanoclay, alumina, carbon nanotubes, nanocarbon, $\mathrm{TiO}_{2}, \mathrm{SiC}, \mathrm{PZT}$.

Nanoclays are affordable nanofillers that impart high strength, low permeability and excellent flame-retardant properties suitable for aerospace structures. MMT nanocomposites and DOPO-based phosphorus tetraglycidyl nanocomposites also satisfy the structural requirements of aerospace. CNTs and CB impart the electrical and thermal conductivity to the nanocomposites structures sufficient to provide lightning strike resistance to aircrafts. Carbon black-based piezoresistive nanocomposite strain gauges show a high gauge factor of 26 that is suitable for vibration-based condition monitoring and SHM in large aircraft structures. CNT-based conductive nanocomposites have also demonstrated the EM shielding and radar-absorbing capabilities for aircrafts. Polyurethane nanocomposite coatings containing carbon nanotubes have lightning resistance, deicing capabilities and EM shielding capabilities as required for commercial and military aircrafts. Apart from structural and coating applications, nanocomposites are developed as lightweight bearings for aerospace and space applications. These are PMNCs like PTFE/TiO and $\mathrm{CMNC}$ like $\mathrm{WC} / \mathrm{DLC} / \mathrm{WS}_{2}$ coatings. Aerospace industry requires repeatable properties of structures for their certifications. This is possible if the nanoparticle content is same throughout and the nanoparticles have uniform size, shape and chirality. In addition, uniform and consistent supply of nanoparticles is required to avoid recertification of parts with new nanoparticles, which is very expensive.

Future research is being focused on the development of processing techniques to enhance dispersion of fillers, reduce the agglomeration and increase the interface properties between the nanofiller and the matrix. To solve these problems, the use of simulation tools to study the enhancement of properties will be beneficial. In addition, the development of low-cost biodegradable nanocomposites will significantly benefit life and environment.

Open Access This article is distributed under the terms of the Creative Commons Attribution 4.0 International License (http://creativecommons. org/licenses/by/4.0/), which permits unrestricted use, distribution, and reproduction in any medium, provided you give appropriate credit to the original author(s) and the source, provide a link to the Creative Commons license, and indicate if changes were made.

Publisher's Note Springer Nature remains neutral with regard to jurisdictional claims in published maps and institutional affiliations.

\section{References}

Ahmad K, Pan W (2009) Dramatic effect of multiwalled carbon nanotubes on the electrical properties of alumina based ceramic nanocomposites. Compos Sci Technol 69:1016-1021

Aldraihem OJ, Akl WN, Baz AM (2009) Nanocomposite functional paint sensor for vibration and noise monitoring. Sens Actuators, A 149:233-240

Alexandre M, Dubois P (2000) Polymer-layered silicate nanocomposites: preparation, properties and uses of a new class of materials. Mater Sci Eng, R 28:1-63

Anand SV, Roy Mahapatra D (2009a) The dynamics of polymerized carbon nanotubes in semiconductor polymer electronics and electro-mechanical sensing. Nanotechnol 20(145707):1-7

Anand SV, Roy Mahapatra D (2009b) Quasi-static and dynamic strain sensing using carbon nanotube/epoxy nanocomposite thin films. Smart Mater Struct 18(045013):1-13

Ando Y, Zhao X, Shimoyama H, Sakai G, Kaneto K (1999) Physical properties of multiwalled carbon nanotubes. Int J Inorg Mater $1: 77-82$

Andrews R, Weisenberger MC (2004) Carbon nanotube polymer composites. Curr Opin Solid State Mater Sci 8:31-37

Armitage NP, Gabriel JCP, Gruner G (2004) Quasi-LangmuirBlodgett thin film deposition of carbon nanotubes. J Appl Phys 95:3228-3230

Aschberger K, Micheletti C, Sokull-Klüttgen B, Christensen FM (2011) Analysis of currently available data for characterising the risk of engineered nanomaterials to the environment and human health-lessons learned from four case studies. Environ Int 37:1143-1156

Ashby MF (1992) Materials selection in mechanical design. Pergamon Press, United Kingdom

Avadhani CV, Chujo Y (1997) Polyimide-silica gel hybrids containing metal salts: preparation via the sol-gel reaction. Appl Organomet Chem 11:153-161

Awaji H, Choi SM, Yagi E (2002) Mechanisms of toughening and strengthening in ceramic-based nanocomposites. Mech Mater 34:411-422

Azeez AA, Rhee KY, Park SJ, Hui D (2013) Epoxy clay nanocomposites-processing, properties and applications: a review. Compos Part B 45:308-320 
Baer DR, Burrows PE, El-Azab AA (2003) Enhancing coating functionality using nanoscience and nanotechnology. Prog Org Coat 47:342-356

Bahadur S, Sunkara C (2005) Effect of transfer film structure, composition and bonding on the tribological behaviour of polyphenylene sulfide filled with nano particles of $\mathrm{TiO}_{2}, \mathrm{ZnO}$, $\mathrm{CuO}$ and SiC. Wear 258:1411-1421

Baikoula NM, Kirger-Kocsis J (2002) Review Processes and influencing parameters of the solid particle erosion of polymers and their composites. J Mater Sci 37:3807-3820

Becher PF (1991) Microstructural design of toughened ceramics. J Am Ceram Soc 74:255-269

Bharadwaj RK (2001) Modeling the barrier properties of polymer layered silicate nanocomposites. Macromol 34:9189-9192

Bhushan B, Gupta BK (1991) Handbook of tribology: materials, coatings, and surface treatments. McGraw-Hill Publishing, New York

Biercuk MJ, Llaguno MC, Radosavljevic M, Hyun JK, Johnson AT, Fischer JE (2002) Carbon nanotube composites for thermal management. Appl Phys Lett 80:2767-2769

Bierwagen GP, Tallman DE (2001) Choice and measurement of crucial aircraft coatings system properties. Prog Org Coat 41:201-216

Blackford R (1998) Performance demands on aerospace paints relative to environmental legislation. Aircr Eng Aerosp Tec 70:451-455

Blossey R (2003) Self-cleaning surfaces - virtual realities. Nat Mater 2:301-306

Bogue R (2011) Nanocomposites: a review of technology and applications. Assembly Autom 31:106-112

Bourbigot S, Bras ML, Dabrowski F, Gilman JW, Kashiwagi T (2000) PA-6 clay nanocomposite hybrid as char forming agent in intumescent formulations. Fire Mater 24:201-208

Bradford PD, Wang X, Zhao H, Maria JP, Jia Q, Zhu YT (2010) A novel approach to fabricate high volume fraction nanocomposites with long aligned carbon nanotubes. Compos Sci Technol 70:1980-1985

Brampton CJ, Pickering SG, Bowen CR, Kim AH, Buschhorn ST, Lee J, Wardle BL (2014) Actuation of bistable laminates by conductive polymer nanocomposites for use in thermal-mechanical aerosurface de-icing. 54th AIAA/ASME/ASCE/AHS/ASC Conf., National Harbor, Maryland

Briscoe BJ, Pelillo E, Sinha SK (1996) Scratch hardness and deformation maps for polycarbonate and polyethylene. Polym Eng Sci 36:2996-3005

Buschhorn ST, Kessler SS, Lachman N, Gavin J, Thomas G, Wardle BL (2013) Electrothermal icing protection of aerosurfaces using conductive polymer nanocomposites. 54th AIAA/ASME/ASCE/ AHS/ASC Conf., Boston, Massachusetts

Camargo PHC, Satyanarayana KG, Wypych F (2009) Nanocomposites: synthesis, structure, properties and new application opportunities. Mater Res 12:1-39

Cassie ABD, Baxter S (1944) Wettability of porous surfaces. Trans Faraday Soc 40:546-551

Chakradhar RPS, Prasad G, Bera P, Anandan C (2014) Stable superhydrophobic coatings using PVDF-MWCNT nanocomposite. Appl Surf Sci 301:208-215

Chattopadhyay DK, Raju KVSN (2007) Structural engineering of polyurethane coatings for high performance applications. Prog Polym Sci 32:352-418

Cho J, Boccaccini AR, Shaffer MSP (2009) Ceramic matrix composites containing carbon nanotubes. J Mater Sci 44:1934-1951

Choa YH, Yang JK, Kim BH, Jeong YK, Lee JS, Nakayama T, Sekino T, Niihara K (2003) Preparation and characterization of metal/ceramic nanoporous nanocomposite powders. J Magn Magn Mater 266:12-19

Choi SM, Awaji H (2005) Nanocomposites: a new material design concept. Sci Technol Adv Mater 6:2-10

Chung DDL (2001) Electromagnetic interference shielding effectiveness of carbon material. Carbon 39:279-285

Curtin WA, Sheldon BW (2004) CNT - reinforced ceramics and metals. Mater Today 7:44-49

Daben Y (1990) Composite piezoelectric film made from PVDF polymer and PCM-PZT ferroelectric ceramics. Ferroelectr 101:291-296

Dalton AB, Collins S, Munoz E, Razal JM, Ebron VH, Ferraris JP, Coleman JN, Kim BG, Baughman RH (2003) Super-tough carbon-nanotube fibres: these extraordinary composite fibres can be woven into electronic textiles. Nature 423:703-703

Dasari A, Yu ZZ, Mai YW (2009) Fundamental aspects and recent progress on wear/scratch damage in polymer nanocomposites. Mater Sci Eng, R 63:31-80

De Rosa IM, Sarasini F, Sarto MS, Tamburrano A (2008) EMC impact of advanced carbon fiber/carbon nanotube reinforced composites for next-generation aerospace applications. IEEE Trans Electromagn Compat 50:556-563

De Volder MFL, Tawfick SH, Baughman RH, Hart AJ (2013) Carbon nano tubes: present and future commercial applications. Sci 339:535-539

Diamanti K, Soutis C (2010) Structural health monitoring techniques for aircraft composite structures. Prog Aerosp Sci 46:342-352

Dinca I, Ban C, Stefan A, Pelin G (2012) Nanocomposites as advanced materials for aerospace industry. INCAS Bull 4:73-83

Dodds JS, Meyers FN, Loh KJ (2011) Piezoelectric characterization of PVDF-TrFE thin films enhanced with $\mathrm{ZnO}$ nanoparticles. IEEE Sens J 12:1889-1890

Dreher KL (2004) Health and environmental impact of nanotechnology: toxicological assessment of manufactured nanoparticles. Toxicol Sci 77:3-5

Dresselhaus MS, Dresslhaus G, Avouris P (2001) Carbon nanotubes: Synthesis, structure, properties and applications. Springer Verlag, Berlin

Egusa S, Iwasawa N (1998) Piezoelectric paints as one approach to smart structural materials with health-monitoring capabilities. Smart Mater Struct 7:438-445

Favier V, Cavaille JV, Canova GR, Shrivastava SC (1997) Mechanical percolation in cellulose whisker nanocomposites. Polym Eng Sci 37:1732-1739

Ferrick MG, Mulherin ND, Haehnel RB, Coutermarch BA, Durell GD, Tantillo TJ, St. Clair TL, Weiser ES, Cano RJ, Smith TM, Martinez EC (2006) Double lap shear testing of coating modified ice adhesion to liquid oxygen feed line bracket, space shuttle external tank. Storming Media NASA order NNL05AA401

Ferroni LP, Pezzotti G, Isshiki T, Kleebe HJ (2001) Determination of amorphous interfacial phases in $\mathrm{Al}_{2} \mathrm{O}_{3} / \mathrm{SiC}$ nanocomposites by computer-aided high-resolution electron microscopy. Acta Mater 49:2109-2113

Fischer H (2003) Polymer nanocomposites: from fundamental research to specific applications. Mater Sci Eng, C 23:763-772

Friedrich K (1993) Advances in composite tribology. Elsevier, Amsterdam, pp 209-273

Friedrich K, Zhang Z, Schlarb AK (2005) Effects of various fillers on the sliding wear of polymer composites. Compos Sci Technol 65:2329-2343

Gagne M, Therriault D (2014) Lightning strike protection of composites. Prog Aerosp Sci 64:1-16

Gairola SP, Verma V, Kumar L, Dar MA, Annapoorni S, Kotnala RK (2010) Enhanced microwave absorption properties in polyaniline and nano-ferrite composite in X-band. Synth Met 160:2315-2318 
Gall K, Dunn ML, Liu Y, Finch D, Lake M, Munshi NA (2002) Shape memory polymer nanocomposites. Acta Mater 50:5115-5126

Gall K, Dunn ML, Liu Y, Stefanic G, Balzar D (2004) Internal stress storage in shape memory polymer nanocomposites. Appl Phys Lett 85:290-292

Gangopadhyay R, De A (2000) Conducting polymer nanocomposites: a brief overview. Chem Mater 12:608-622

Ganzhorn M, Vijayaraghavan A, Dehm S, Hennrich F, Green AA, Fichtner M, Voigt A, Rapp M, von Lohneysen H, Hersam MC, Kappes MM, Krupke R (2011) Hydrogen sensing with diameterand chirality-sorted carbon nanotubes. ACS Nano 5:1670-1676

Gent RW, Dart NP, Cansdale JT (2000) Aircraft Icing. Philos Trans R Soc A 358:2873-2911

Giannelis EP (1996) Polymer layered silicate nanocomposites. Adv Mater 8:29-35

Giannelis EP (1998) Polymer-layered silicate nanocomposites: synthesis, properties and applications. Appl Organomet Chem 12:675-680

Gilman JW, Kashiwagi T, Lichtenhan JD (1977) Nanocomposites: a revolutionary new flame retardant approach. SAMPE J 33:40-46

Giridhara G, Rathod VT, Naik S, Mahapatra DR, Gopalakrishnan S (2010) Rapid localization of damage using a circular sensor array and Lamb wave based triangulation. Mech Syst Sig Process 24:2929-2946

Giurgiutiu V (2014) Structural health monitoring with piezoelectric wafer active sensors. Academic Press, Cambridge

Giurgiutiu V, Soutis C (2012) Enhanced composites integrity through structural health monitoring. Appl Compos Mater 19:813-829

Gonnet P, Liang Z, Choi ES, Kadambala RS, Zhang C, Brooks JS, Wang B, Kramer L (2006) Thermal conductivity of magnetically aligned carbon nanotube buckypapers and nanocomposites. Curr Appl Phys 6:119-122

Graham RH (1997) SR-71 Revealed, Motor books Int, WI, USA, pp 224

Haque A, Shamsuzzoha M, Hussain F, Dean D (2003) S2-glass/epoxy polymer nanocomposites: manufacturing, structures, thermal and mechanical properties. J Compos Mater 37:1821-1837

Herron N, Thorn DL (1998) Nanoparticles: uses and relationships to molecular cluster compounds. Adv Mater 10:1173-1184

Howarth GA (2003) Polyurethanes, polyurethane dispersions and polyureas: past, present and future. Surf Coat Int Part B: Coat Trans 86:111-118

Hsu CP, Chang LY, Chiu CW, Lee PTC, Lin JJ (2013) Facile fabrication of robust superhydrophobic epoxy film with polyamine dispersed carbon nanotubes. ACS Appl Mater Interfaces 5:538-545

Iijima S (1991) Helical microtubules of graphitic carbon. Nature 354:56-58

Im JS, Lee SK, In SJ, Lee YS (2010) Improved flame retardant properties of epoxy resin by fluorinated MMT/MWCNT additives. J Anal Appl Pyrolysis 89:225-235

Inam F, Bhat BR, Vo T, Daoush WM (2014) Structural health monitoring capabilities in ceramic-carbon nanocomposites. Ceram Int 40:3793-3798

Jackson HF, Jayaseelan DD, Lee WE, Reece MJ, Inam F, Manara D, Casoni CP, Bruycker FD, Boboridis K (2010) Laser melting of spark plasma-sintered zirconium carbide: thermo physical properties of a generation IV very high-temperature reactor material. Int J Appl Ceram Technol 7:316-326

Jain A, Kumar JS, Mahapatra DR, Rathod VT (2013a) Development of $\mathrm{P}(\mathrm{VDF}-\mathrm{TrFE})$ films and its quasi-static and dynamic strain response. Int J Eng Res Technol 2:2598-2605

Jain A, Kumar JS, Srikanth S, Rathod VT, Mahapatra DR (2013b) Sensitivity of polyvinylidene fluoride films to mechanical vibration modes and impact after optimizing stretching conditions. Polym Eng Sci 53:707-715
Jain A, Kumar JS, Kumar MR, Ganesh AS, Srikanth S (2014) PVDFPZT composite films for transducer applications. Mech Adv Mater Struct 21:181-186

Kang I, Schulz MJ, Kim JH, Shanov V, Shi D (2006) Vessel in Shanov and Donglu Shi, A carbon nanotube strain sensor for structural health monitoring. Smart Mater Struct $15: 737-748$

Knite M, Teteris V, Kiploka A, Kaupuzs J (2004) Polyisoprenecarbon black nanocaomposites as tensile strain and pressure sensor materials. Sens Actuators, A 110:142-149

Kojima Y, Usuki A, Kawasumi M, Okada A, Fukushima Y, Kurauchi T, Kamigaito O (1993) Mechanical properties of Nylon 6-clay hybrid. J Mater Res 8:1185-1189

Krishnamoorti R, Vaia RA, Giannelis EP (1996) Structure and dynamics of polymer-layered silicate nanocomposites. Chem Mater 8:1728-1734

Lancaster JK (1990) Material-specific wear mechanisms: relevance to wear modelling. Wear 141:159-183

Lesser M (1995) Thirty years of liquid impact research: a tutorial review. Wear 186:28-34

Li HJ, Lu WG, Li JJ, Bai XD, Gu CZ (2005) Multichannel ballistic transport in multiwall carbon nanotubes. Phys Rev Lett 95:086601-1

Li C, Thostenson ET, Chou TW (2007) Dominant role of tunneling resistance in the electrical conductivity of carbon nanotubebased composites. Appl Phys Lett 91:223114-1

Lim SC, Ashby MF (1987) Overview no. 55 wear-mechanism maps. Acta Metall 35:1-24

Liu Y, Song D, Wu C, Leng J (2014) EMI shielding performance of nanocomposites with MWCNTs, nanosized $\mathrm{Fe}_{3} \mathrm{O}_{4}$ and $\mathrm{Fe}$. Compos Part B 63:34-40

Loh KJ, Chang D (2011) Zinc oxide nanoparticle-polymeric thin films for dynamic strain sensing. J Mater Sci 46:228-237

Lu J, Chen X, Lu W, Chen G (2006) The piezoresistive behaviors of polyethylene/foliated graphite nanocomposites. Eur Polym J 42:1015-1021

Luan J, Wang S, Hu Z, Zhang L (2012) Synthesis techniques, properties and applications of polymer nanocomposites. Curr Org Synth 9:114-136

Lyons J, Ko F (2005) Feature article: melt electrospinning of polymers: A review. Polym News: Polym Sci Mon 30:170-178

Mahieux CA (2006) Environmental degradation in industrial composites. Elsevier, Chicago

Martin R (2008) Ageing of composites. Woodhead Publishing, Cambridge

Meda L, Marra G, Galfetti L, Inchingalo S, Severini F, Luca LD (2005) Nano-composites for rocket solid propellants. Compos Sci Technol 65:769-773

Meenakshi KS, Sudhan EPJ, Kumar SA, Umapathy MJ (2011) Development and characterization of novel DOPO based phosphorus tetraglycidyl epoxy nanocomposites for aerospace applications. Prog Org Coat 72:402-409

Mendes SF, Costa CM, Sencadas V, Nunes JS, Cost P, Gregorio R Jr, Mendez SL (2009) Effect of the ceramic grain size and concentration on the dynamical mechanical and dielectric behavior of Poly(vinilidene fluoride) $/ \mathrm{Pb}\left(\mathrm{Zr}_{0.53} \mathrm{Ti}_{0.47}\right) \mathrm{O}_{3}$ composites. Appl Phys A 96:899-908

Meng Q, Hu J (2009) A review of shape memory polymer composites and blends. Compos Part A 40:1661-1672

Messersmith PB, Giannelis EP (1994) Synthesis and characterization of layered silicate-epoxy nanocomposites. Chem Mater 6:1719-1725

Meyers FN, Loh KJ, Dodds JS, Baltazar A (2013) Active sensing and damage detection using piezoelectric zinc oxide-based nanocomposites. Nanotechnol 24:185501 
Micheli D, Apollo C, Pastore R, Morles RB, Laurenzi S, Marchetti M (2011a) Nanostructured composite materials for electromagnetic interference shielding applications. Acta Astronaut 69:747-757

Micheli D, Apollo C, Pastore R, Morles RB, Marchetti M, Gradoni G (2011b) Electromagnetic characterization of composite materials and microwave absorbing modelling. In: Reddy B (ed) Advances in nanocomposites - synthesis, characterization and industrial applications. InTech, Croatia, pp 359-384

Mishchenko L, Hatton B, Bahadur V, Taylor JA, Krupenkin T, Aizenberg J (2010) Design of ice-free nanostructured surfaces based on repulsion of impacting water droplets. ACS Nano 4:7699-7707

Miyoshi K, Wu RLC, Lanter WC (1997) Friction and wear of diamond like carbon on fine-grain diamond. Tribol Lett 3:141-145

Nalwa HS (2000) Handbook of nanostructured materials and technology. Academic Press, New York

Neo CP, Varadan VK (2004) Optimization of carbon fibercomposite for microwave absorber. IEEE Trans Electromagn Compat 46:102-106

Ni Y, Zheng S, Nie K (2004) Morphology and thermal properties of inorganic-organic hybrids involving epoxy resin and polyhedral oligomeric silsesquioxanes. Polym 45:5557-5568

Ounaies Z, Park C, Wise KE, Siochi EJ, Harrison JS (2003) Electrical properties of single wall carbon nanotube reinforced polyimide composites. Compos Sci Technol 63:1637-1646

Pandey JK, Reddy KR, Kumar AP, Singh RP (2005) An overview on the degradability of polymer nanocomposites. Polym Degrad Stab 88:234-250

Park JG, Louis J, Cheng Q, Bao J, Smithyman J, Liang R, Wang B, Zhang C, Brooks JS, Kramer L, Fanchasis P, Dorough D (2009) Electromagnetic interference shielding properties of carbon nanotube buckypaper composites. Nanotechnol 20(415702):1-7

Peigney A, Laurent C, Flahaut E, Rousset A (2000) Carbon nanotubes in novel ceramic matrix nanocomposites. Ceram Int 26:677-683

Peng HX (2011) Polyurethane nanocomposite coatings for aeronautical applications. In: Leng J, Lau AKT (eds) Multifunctional polymer nanocomposites. CRC Press, Boca Raton, pp 337-387

Ping S (1980) Fluctuation-induced tunneling conduction in disordered materials. Phys Rev B 21:2180-2195

Prasad S, Zabinski J (1997) Lubricants: super slippery solids. Nat 387:761-763

Ramasubramaniam R, Chen J (2003) Homogeneous carbon nanotube/ polymer composites for electrical applications. Appl Phys Lett 83:2928-2930

Rathod VT, Mahapatra DR (2010) Lamb wave based monitoring of plate-stiffener deboding using a circular array of piezoelectric sensors. Ini J Smart Sens Intell Syst 3:27-44

Rathod VT, Mahapatra DR (2011) Ultrasonic Lamb wave based monitoring of corrosion type of damage in plate using a circular array of piezo electric transducers. NDT Int 44:628-636

Rathod VT, Mahapatra DR, Jain A, Gayathri A (2010) Characterization of a large area PVDF thin film for electro-mechanical and ultrasonic sensing applications. Sens Actuators, A 163:164-171

Rathod VT, Hiremath SR, Mahapatra DR (2014) Strength and fatigue life evaluation of composite laminate with embedded sensors. Proc SPIE, 9062

Ray SS, Bousmina M (2005) Biodegradable polymers and their layered silicate nanocomposites: in greening the 21st century materials world. Prog Mater Sci 50:962-1079

Ray SS, Okamoto M (2003) Polymer/layered silicate nanocomposites: a review from preparation to processing. Prog Polym Sci 28:1539-1641

Ray SS, Yamada K, Okamoto M, Ueda K (2002) Polylactide-layered silicate nanocomposite: a novel biodegradable material. Nano Lett 2:1093-1096
Reghu M, Yoon CO, Yang CY, Moses D, Smith P, Heeger AJ, Cao Y (1994) Transport in polyaniline networks near the percolation threshold. Phys Rev B 50:13931-13941

Rupke EJP (2002) Lightning direct effects handbook. Lightning Technologies Inc., Pittsfield

Sawyer WG, Freudenberg KD, Bhimaraj P, Schadler LS (2003) A study on the friction and wear behavior of PTFE filled with alumina nanoparticles. Wear 254:573-580

Shao X, Liu W, Xue Q (2004) The tribological behavior of micrometer and nanometer $\mathrm{TiO}_{2}$ particle-filled poly (phthalazine ether sulfone ketone) composites. J Appl Polym Sci 92:906-914

She J, Inoue T, Suzuki M, Sodeoka S, Ueno K (2000) Mechanical properties and fracture behavior of fibrous $\mathrm{Al}_{2} \mathrm{O}_{3} / \mathrm{SiC}$ ceramics. J Eur Ceram Soc 20:1877-1881

Sheng P, Sichel EK, Gittleman JI (1978) Fluctuation-induced tunneling conduction in carbon-polyvinylchloride composites. Phys Rev Lett 40:1197-1200

Shi G, Zhang MQ, Rong MZ, Wetzel B, Friedrich K (2003) Friction and wear of low nanometer $\mathrm{Si}_{3} \mathrm{~N}_{4}$ filled epoxy composites. Wear 254:784-796

Shi YJ, Feng X, Wang HY, Liu C, Lu XH (2007) Effects of filler crystal structure and shape on the tribological properties of PTFE composites. Tribol Int 40:1195-1203

Singer IL, Fayeulle S, Ehni PD (1996) Wear behavior of triodesputtered $\mathrm{MoS}_{2}$ coatings in dry sliding contact with steel and ceramics. Wear 195:7-20

Sorensen PA, Kiil S, Dam-Johansen K, Weinell CE (2009) Anticorrosive coatings: a review. J Coat Technol Res 6:135-176

Sreekala MS, Eger C (2005) Property improvements of an epoxy resin by nanosilica particle reinforcement. In: Friedrich K, Fakirov $S$, Zhang Z (eds) polymer composites: From nano - to macro-scale. Springer, US, pp 91-105

Stan A, Dinca I, Ban C, Ilina S, Donescu D, Paven H, Dumitrache L, Gavrila L, Voicu I (2011) Epoxy- layered silicate and epoxy MWCNTs nanocomposites. Appl Mech Mater 146:160-169

Stauffer D, Aharony A (1994) Introduction to percolation theory. Taylor \& Francis, London

Sternitzke M (1997) Review: structural ceramic nanocomposites. J Eur Ceram Soc 17:1061-1082

Sundararaman V, Rathod VT, Mahapatra DR (2015) Temperature compensation in CNT-composite distributed strain sensors. Proc SPIE, 9436

Suresh MB, Yeh TH, Yu CC, Chou CC (2009) Dielectric and ferroelectric properties of polyvinylidene fluoride ( $\mathrm{PVDF})-\mathrm{Pb}_{0.52}$ $\mathrm{Zr}_{0.48} \mathrm{TiO}_{3}(\mathrm{PZT})$ nano composite films. Ferroelectr 381:80-86

Theng BKG (1979) Formation and properties of clay-polymer complexes. Elsevier, Amsterdam

Thompson CM, Herring HM, Gates TS, Connel JW (2003) Preparation and characterization of metal oxide/polyimide nanocomposites. Compos Sci Technol 63:1591-1598

Thostenson ET, Li C, Chou TW (2005) Nanocomposites in context. Compos Sci Technol 65:491-516

Tjong SC, Wang GS (2004) High-cycle fatigue properties of Al-based composites reinforced with in situ $\mathrm{TiB}_{2}$ and $\mathrm{Al}_{2} \mathrm{O}_{3}$ particulates. Mater Sci Eng, A 386:48-53

Turri S, Torlaj L, Piccinini F, Levi M (2010) Abrasion and nanoscratch in nanostructured epoxy coatings. J Appl Polym Sci 118:1720-1727

Usuki A, Kojima Y, Kawasumi M, Okada A, Fukushima Y, Kurauchi T, Kamigaito O (1993) Synthesis of nylon 6-clay hybrid. J Mater Res 8:1179-1184

Vaia RA, Giannelis EP (1997) Polymer melt intercalation in organically-modified layered silicates: model predictions and experiment. Macromol 30:8000-8009 
Vaia RA, Ishii H, Giannelis EP (1993) Synthesis and properties of two-dimensional nanostructures by direct intercalation of polymer melts in layered silicates. Chem Mater 5:1694-1696

Vaia RA, Price G, Ruth PN, Nguyen HT, Lichtenhan J (1999) Polymerrlayered silicate nanocomposites as high performance ablative materials. Appl Clay Sci 15:67-92

van den Ende DA, de Almeida P, van der Zwaag S (2007) Piezoelectric and mechanical properties of novel composites of PZT and a liquid crystalline thermosetting resin. J Mater Sci 42:6417-6425

Van Krevelen DW (1990) Properties of polymers: their correlation with chemical structure: Their numerical estimation and prediction from additive group contributions. Elsevier, Amsterdam

Voevodin AA, Capano MA, Safriet AJ, Donley MS, Zabinski JS (1996a) Combined magnetron sputtering and pulsed laser deposition of carbides and diamond-like carbon films. Appl Phys Lett 69:188-190

Voevodin AA, Phelps AW, Zabinski JS, Donley MS (1996b) Friction induced phase transformation of pulsed laser deposited diamondlike carbon. Diamond Relat Mater 5:1264-1269

Voevodin AA, Bultman J, Zabinski JS (1998) Investigation into threedimensional laser processing of tribological coatings. Surf Coat Technol 107:12-19

Voevodin AA, O’Neill JP, Zabinski JS (1999) Nanocomposite tribological coatings for aerospace applications. Surf Coat Technol 116:36-45

Vora RH, Vora M (2006) 1,2'-Bis(4-aminophenoxy)benzene based designed fluoro-poly(ether-imide)/MMT clay nanocomposites: synthesis and properties for high performance applications. Mater Sci Eng, B 132:90-102

Wang ZL, Song J (2006) Piezoelectric nanogenerators based on zinc oxide nanowire arrays. Sci 312:242-246

Wang QH, Xu J, Shen W, Liu W (1996) An investigation of the friction and wear properties of nanometer $\mathrm{Si}_{3} \mathrm{~N}_{4}$ filled PEEK. Wear 196:82-86

Wang QH, Xu J, Shen W, Xue Q (1997a) The effect of nanometer SiC filler on the tribological behavior of PEEK. Wear 209:316-321

Wang Q, Xue Q, Shen W (1997b) The friction and wear properties of nanometre $\mathrm{SiO}_{2}$-filled polyetheretherketone. Tribol Int 30:193-197

Wang Q, Xue Q, Shen W, Zhang J (1998) The friction and wear properties of nanometer $\mathrm{ZrO}_{2}$-filled polyetheretherketone. J Appl Polym Sci 69:135-141

Wang B, Liang R, Zhang C, Funches P, Kramer L (2005a) Investigation of lightning and EMI shielding properties of
SWNT Buckypaper nanocomposites, DTIC Accession Number: ADA430333

Wang YJ, Pan Y, Zhang XW, Tan K (2005b) Impedance spectra of carbon black filled high-density polyethylene composites. J Appl Polym Sci 98:1344-1350

Weisenberger MC, Grulke EA, Jacques D, Rantell AT, Andrews R (2003) Enhanced mechanical properties of polyacrylonitrile: multiwall carbon nanotube composite fibers. J Nanosci Nanotechnol 3:535-539

Wenzel RN (1936) Resistance of solid surfaces to wetting by water. Ind Eng Chem 28:988-994

Wetzel B, Haupert F, Friedrich K, Zhang MQ, Rong MZ (2002) Impact and wear resistance of polymer nanocomposites at low filler content. Polym Eng Sci 42:1919-1927

Wetzel B, Haupert F, Zhang MQ (2003) Epoxy nanocomposites with high mechanical and tribological performance. Compos Sci Technol 63:2055-2067

Williams JA (1996) Analytical models of scratch hardness. Tribol Int 29:675-694

Xia H, Song M (2006) Preparation and characterization of polyurethane grafted single-walled carbon nanotubes and derived polyurethane nanocomposites. J Mater Chem 16:1843-1851

Yano K, Usuki A, Okada A (1997) Synthesis and properties of polyimide-clay hybrid films. J Polym Sci, Part A: Polym Chem 35:2289-2294

Yoon YH, Song JW, Kim D, Kim J, Park JK, Oh SK, Han CS (2007) Transparent film heater using single-walled carbon nanotubes. Adv Mater 19:4284-4287

Youssef AM (2013) Polymer nanocomposites as a new trend for packaging applications. Polym Plast Technol Eng 52:635-660

Zeppetelli D, Habashi WG (2012) In-flight icing risk management through computational fluid dynamics-icing analysis. J Aircr 49:611-621

Zhang MQ, Rong MZ, Yu SL, Wetzel B, Friedrich K (2002) Effect of particle surface treatment on the tribological performance of epoxy based nanocomposites. Wear 253:1086-1093

Zhang R, Zhang Y, Zhang Q, Xie H, Qian W, Wei F (2013) Growth of half-meter long carbon nanotubes based on schulz-flory distribution. ACS Nano 7:6156-6161

Zhao Q, Bahadur S (1999) The mechanism of filler action and the criterion of filler selection for reducing wear. Wear 229:660-668

Zhu R, Wang D, Xiang S, Zhou Z, Ye X (2008) Piezoelectric characterization of a single zinc oxide nanowire using a nanoelectromechanical oscillator. Nanotechnol 19:285712/ 285711 